\title{
Fracture properties of porous yttria-stabilized zirconia under micro-compression testing
}

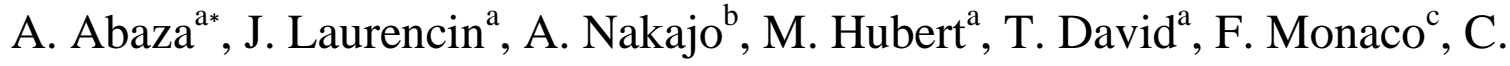 \\ Lenser $^{\mathrm{d}}, \mathrm{S}$. Meille \\ ${ }^{\text {a }}$ CEA-LITEN, 17 rue des martyrs, F-30854 Grenoble, France \\ ${ }^{\mathrm{b}}$ Ecole Polytechnique Fédérale de Lausanne, 1015 Lausanne, Switzerland \\ ${ }^{\mathrm{c}}$ European Synchrotron Radiation Facility (ESRF), 71 avenue des Martyrs, 38000, Grenoble, \\ France \\ ${ }^{\mathrm{d}}$ Institute of Energy and Climate Research - Materials Synthesis and Processing (IEK-1), \\ Forschungszentrum Jülich GmbH, 52425 Jülich, Germany \\ ${ }^{\mathrm{e}}$ Univ Lyon, INSA Lyon, UCBL, MATEIS, CNRS UMR 5510, 20 Av. A. Einstein, F-69621 \\ Villeurbanne, France
}

\begin{abstract}
.
Micro-compression tests were carried out on pillars of $60 \mu \mathrm{m}$ in diameter, milled by plasma focused ion beam in porous Yttria-Stabilized Zirconia (YSZ) pellets. The fracture properties were determined over a wide range of porosities (33\%-63\%) for 8YSZ and at a given pore volume fraction of $63 \%$ for 3 YSZ. The mechanical properties determined from testing were reproducible thanks to the homogeneity of the microstructures. The Young's modulus was estimated as a function of the porosity from the unloading curve of tests stopped before fracture. The experiments conducted until the total rupture allowed measuring the compressive fracture strength, which was found to decrease when increasing the porosity. Specimen tested and unloaded just before the total fracture were cross-sectioned by focused ion beam - scanning electron microscope. A transition was detected from a brittle behavior, with macro-cracks parallel to the direction of solicitation, to a diffuse damage with microcracks, when increasing the porosity.
\end{abstract}

Keywords: porous yttria-stabilized zirconia, micro-compression, micro-pillar, compressive fracture strength, fracture mode.

\footnotetext{
${ }^{*}$ Corresponding author. Tel.: +33 0438782210

E-mail address: amira.abaza@cea.fr (A. Abaza); Jerome.laurencin@cea.fr (J. Laurencin); sylvain.meille@insalyon.fr (S. Meille).
} 


\section{Introduction}

Material fracture properties play a key role in the mechanical design of technological devices. The identification of their failure modes during usage is also essential to optimize their robustness and lifetime. In this frame, various studies have been already devoted to the fracture of porous ceramics. This class of functional materials can be used in many domains such as electronics, chemistry, biology and energy [1-5]. Porous ceramics are widely employed as they take advantage of the attractive properties of ceramic known to be stable in very aggressive environments [1-8]. They also exhibit a good thermal shock resistance and a low thermal conductivity. Moreover, ceramics are characterized by a low dielectric constant and they are highly resistant to corrosion, in particular to oxidation. These intrinsic characteristics of the dense ceramics can be combined to the properties of porous materials for many applications, including catalyst supports, filters, etc. Furthermore, the processing of porous ceramics has been significantly improved in the recent years [2,9,10]. Indeed, the volume fraction, distribution, orientation, size and shape of both solid and porosity phases can be nowadays exhaustively controlled during manufacturing. It is therefore possible to design the microstructure of a porous material in accordance with the targeted application.

In the domain of energy, there is a growing interest for porous ceramics as multifunctional materials. For instance, they constitute the key components of Solid Oxide Cells (SOC) used for fuel cell (SOFC) and electrolysis (SOEC) applications [11]. This technology operates at high temperature and provides very high efficiencies without the use of expensive electrocatalyst [12]. SOC is composed of a dense electrolyte sandwiched between two porous electrodes [13,14]. The electrolyte is classically made of Yttria Stabilized Zirconia (YSZ) while the hydrogen electrode is a cermet of Nickel and YSZ (Ni-YSZ) [15,16]. YSZ exhibits a maximum in ionic conductivity to around 8.5-9 \% molar of Yttria whereas a lower doping rate at $3 \%$ molar of Yttria (3YSZ) provides a better mechanical robustness [13,17]. A zirconia stabilized with $8 \%$ molar of Yttria (8YSZ) is thus typically chosen for the electrolyte to ensure a high ionic conductivity. As the hydrogen electrode is generally used as the mechanical support for the cell, 3 YSZ ceramic is sometime preferred for its better fracture properties despite its lower ionic conductivity as compared to 8YSZ.

Despite the various advantages of the high-temperature technology, the SOC is still submitted to degradation phenomena that limit its lifetime. For instance, the cell is subjected to significant internal stresses due to the high operating temperature and the mismatch in thermal expansion coefficients between the SOC components. In particular, these thermomechanical 
loadings can lead to a mechanical damage in the hydrogen electrode with the creation of micro-cracks within the YSZ backbone [18-21]. Moreover, the Ni in the hydrogen electrode is liable to re-oxidize into $\mathrm{NiO}$ in case of system failures such as the re-introduction of air during the system shutdown. Because of the Ni volume expansion upon re-oxidation, high tensile stresses are generated in the YSZ skeleton leading to the generation of micro-cracks [22-25]. It has been shown that the mechanical damage in the hydrogen electrode can affect significantly the overall cell performance [22,25-27]. In this frame, several studies have been already dedicated to assess the mechanical degradation of the hydrogen electrode and to quantify its impact on the global cell performances $[23,28,29]$. However, data on the fracture properties of YSZ ceramic as a function of its porosity is currently incomplete for the prediction of local fracture in the electrode. The toughness of the 3YSZ has been measured by double-torsion over a large range of porosity [30]. Nevertheless, the compressive fracture strength for the 8YSZ has been measured only at high porosity (65-77\%) on millimetric macroscopic samples [31,32] whereas no data is available for the 3YSZ. As the thickness of the cermet substrate does usually not exceed $400 \mu \mathrm{m}$ [33], a special care should be taken when using fracture properties measured at the macroscopic scale. Indeed, a change in the fracture strength and in the mechanism of fracture can occur when reducing the sample size. To date, no data is available on the mechanical properties of porous YSZ at small scale, even if micromechanical testing is becoming more common on other types of materials [34-37].

In the last decades, micro-mechanics has received ever increasing interest thanks to advances in sample manufacturing and preparation techniques such as electrodeposition and Focused Ion Beam (FIB) machining [38-40]. In the literature, sophisticated geometries such as microcantilever and micro-tensile specimen have been tested under bending and tensile tests [4143] whereas micro-pillars have been tested under uniaxial compression [39,44]. To date, micro-compression testing has been conducted on dense materials such as gold, zirconia and metallic alloys, on composite such as wood, and porous metals such as silver [34,38,45-47]. To the best of our knowledge, the mechanical characterization of porous ceramics under micro-compression have never been addressed and thus adequate methods for the preparation of porous ceramic micro-pillars are yet to be developed.

The aim of this work is to characterize the fracture properties of porous YSZ ceramic by the micro-compression testing of pillars with microstructures and dimensions representative of the SOC hydrogen electrode. The study was mainly focused on the characterization of the 8YSZ material as a function of porosity (33-63\%) while the behavior of 3YSZ was 
complementarily investigated at high porosity (63\%). In this objective, micro-pillars in porous 8YSZ and 3YSZ were prepared and tested using a nano-indenter with a flat-punch diamond tip. Subsequently, the compressive fracture strength was measured as a function of the investigated porosity and material. The experimental results were then compared to the few available data obtained with macroscopic samples [31,32]. This comparison allowed addressing sample size effects on the compressive fracture strength. Finally, using a FIB Scanning Electron Microscope (FIB-SEM), microstructural characterizations were obtained after the test to localize the cracks created within the micro-pillars. The fracture mode of the YSZ ceramic in compression was therefore discussed as a function of its porosity.

\section{Experiments and methodology}

\subsection{Sample preparation}

Micro-pillars for the compression tests were milled in macroscopic porous YSZ pellets. The protocols of the sample preparation are detailed in the sections hereafter.

\subsubsection{Pellets at intermediate porosities $(<50 \%)$}

To obtain samples at intermediate porosities $(<50 \%)$, 8 YSZ powder was partial sintered at different temperatures. A commercial Tosoh TZ-8YSB powder was first compacted under a uniaxial compression load of $156 \mathrm{MPa}$. The compacted pellets were then heated in air for five hours to reach the sintering temperature, which was maintained for one hour. Afterwards, all pellets were cooled down to room temperature during five hours. In order to change the pore volume fraction, four different sintering temperatures (i.e. $1270^{\circ} \mathrm{C}, 1230^{\circ} \mathrm{C}, 1200^{\circ} \mathrm{C}$ and $1150^{\circ} \mathrm{C}$ ) were selected based on the $8 Y S Z$ dilatometry curve, leading to pellets with different porosities. It should be noticed that several pellets were produced at each given sintering temperature. After sintering, the pellet dimensions were around $9 \mathrm{~mm}$ in diameter and $3 \mathrm{~mm}$ in thickness. To prepare the pellets for the compression test, their upper surfaces were mechanically polished. The protocol consisted in polishing the samples with a series of diamond suspensions down to $1 \mu \mathrm{m}$ with a last step using a vibratory finishing machine (Struers tetra force 5). As a result, flat surface with limited roughness was obtained. 


\subsubsection{Pellets at high porosities $(>50 \%)$}

To obtain pellets at porosities higher than 50\%, a typical Ni-8YSZ cermet support was used to complement the study. The protocol reported in Laurencin et al. [48] was used to remove the $\mathrm{Ni}$ from the 8YSZ backbone and is briefly reminded hereafter. Firstly, as the cermet is under its oxidized state after manufacturing, the $\mathrm{NiO}$ particles were reduced into $\mathrm{Ni}$. For this purpose, the NiO-YSZ substrate was heated up to $800^{\circ} \mathrm{C}$ at a rate of $5^{\circ} \mathrm{C} \cdot \mathrm{min}^{-1}$ under a gas mixture of $\left(2 \% \mathrm{H}_{2}+\mathrm{Ar}\right)$. The substrate was then maintained under these reducing conditions for $48 \mathrm{~h}$ up to the complete reduction of $\mathrm{NiO}$ into $\mathrm{Ni}$ before being cooled down to room temperature. The substrate in reduced state was then treated two times in a solution of nitric acid $\left(65 \% \mathrm{HNO}_{3}\right)$ for 4 hours at room temperature. This procedure completely removed the $\mathrm{Ni}$, revealing the zirconia backbone. As a result, a highly porous 8 YSZ sample was obtained.

The same protocol was also applied on a Ni-3YSZ cermet support. The highly porous 3YSZ substrate obtained after Ni dissolution was used to compare the fracture properties with 8YSZ at a similar porosity.

\subsubsection{Porous micro-pillars}

The micro-pillars for the mechanical testing were milled in the porous 3YSZ and 8YSZ pellets using a $\mathrm{Xe}^{+}$plasma FIB (pFIB). The pFIB technology was chosen as it is able to form a high current beam allowing to etch specimens in a short time [49-52]. The target dimensions for the micro-pillars were chosen to fulfill specific criteria. Firstly, the size of pillar must be sufficiently large in order to be representative of the electrode microstructure and to neglect the influence of ion irradiation [35,49]. Knowing that the microstructural characteristic length is roughly estimated to $1 \mu \mathrm{m}$ ( $c f$. section 3.2 ), a diameter of at least $40 \mu \mathrm{m}$ is required to be representative of the investigated microstructures [53]. Secondly, an aspect ratio, defined as the ratio between the pillar height and its upper diameter, ranging between 2 and 3 is recommended in the literature for micro-compression testing [54,55]. Thirdly, the pillar section was also chosen considering the measurement range of the nanoindenter force sensor to be able to reach the critical loading triggering the fracture. Considering all these constrains, the target dimensions of the micro-pillars were set to $60 \mu \mathrm{m}$ in diameter and $130 \mu \mathrm{m}$ in height. 
Since ceramic zirconia is an electrical insulator, the milling was carried out under charge neutralizer atmosphere to evacuate the charges, and hence, to minimize ion beam shifting. The milling was performed at an accelerating voltage of $30 \mathrm{kV}$ with a beam current of 0.47 $\mu \mathrm{A}$. This rather low current was chosen as a tradeoff to limit the so-called "curtaining effect" while keeping an acceptable milling time. Indeed, this "curtaining effect" is here promoted by the presence of porosities and absence of electron or ion beam assisted deposition layer when the milling is performed at a too high current, which degrades the external surface of the pillar [56]. In the present work, milling was conducted using circular pattern for a duration of about 4 hours. It is worth noting that the $\mathrm{Xe}^{+}$beam has a Gaussian shape resulting to produce tapered pillars. This geometrical feature can have a significant impact on the compression testing by inducing a significant gradient in the stress field inside the pillar. Therefore, even if the taper angle is unavoidable, it can be minimized by an accurate beam control. In this work, micro-pillars with taper angle not exceeding $7^{\circ}$ were successfully obtained (Fig. 1). It can be noticed that a milling current higher than $0.47 \mu \mathrm{A}$ led to higher taper angle.

With the idea of preparing several pillars in the same porous pellet, labelling each pillar was needed to identify them before testing. Thus, a silver coating was deposited on a small edge of the upper surface of the sample. To ensure a precise positioning of the indenter on the head of the pillar and to avoid any contact with the substrate surface during the compression, a trench of $\approx 100 \mu \mathrm{m}$ surrounding the pillar was milled: this procedure results in a well of $\approx 260 \mu \mathrm{m}$ with the micro-pillar at the center as shown in Fig. 1. Furthermore, the adjacent wells were milled at a minimal distance of $500 \mu \mathrm{m}$ to neglect the influence of the surrounding pillars on the tested one as discussed in Camposilvan et al. [34].

\subsection{Micro-compression testing}

The compression test was selected in this study for several reasons. As previously mentioned, the hydrogen electrode is submitted to complex loadings during the operation as well as in the case of Ni re-oxidation, leading to its mechanical damage. The fracture of the YSZ skeleton occurs in the regions subjected to tensile and bending stresses. In this view, the compression testing of porous YSZ specimens is relevant since it allows generating local tensile stresses in the microstructure. Besides, under compression, an approximately quasi-uniform macroscopic stress distribution is created within the micro-pillar facilitating the analysis of the test results. 
The compression test was performed using a nano-indenter (G200, Keysight technologies, USA) equipped with a circular diamond flat punch tip of $100 \mu \mathrm{m}$ in diameter associated to an optical microscope. This instrument is controlled by a set of parameters, which can affect the experimental results. Before starting the mechanical testing, calibration of the indentation set up is thus required. First, if the flat punch tip surface is not parallel to the top surface of the pillar, non-homogeneous stress distribution can be generated in the pillar with a flexure moment in addition to the solicitation in compression. Attention was thus paid to correct the misalignment between the flat punch tip and the pillar upper surface. For this purpose, the optical microscope was used to correct the tilt angle of the sample surface with respect to the punch tip. Secondly, attention was paid to calibrate the positioning of the indenter on the tested micro-pillar with the microscope.

The compression testing was conducted under monotonic loading at a constant strain rate of $0.05 \mathrm{~s}^{-1}$. As the diameters slightly increase from the top to the bottom in the tapered pillar, a non-uniform stress field is created under compression, with highest stress in the top surface of the pillar. The engineering stress-strain curve was thus computed from the load-displacement data based on the initial pillar geometry (i.e. top surface diameter and total height).

In the present work, for each material tested (either $8 \mathrm{YSZ}$ or $3 \mathrm{YSZ}$ at a given porosity), at least five pillars were compressed until total failure to measure the compressive fracture strength. Complementary experiments on additional pillars consisted in stopping just before the samples collapse in order to detect the cracks created within the YSZ skeleton and thus to assess the material damage behavior.

\subsection{Microstructural characterizations}

The validation of the protocol applied for the preparation of porous YSZ samples ( $c f$. section 2.1) as well as the detection of the damage after testing were carried out using several microstructural characterization techniques.

\subsubsection{Scanning Electron Microscopy (SEM) observations}

After the sintering step, polished cross-sections of each material were observed by Scanning Electron Microscopy (SEM) to assess the microstructure homogeneity and to estimate the sample porosity. For this purpose, one sample from each batch was impregnated with an 
epoxy resin to fill the pores, then subsequently cut and polished to prepare the cross-section for SEM imaging. As zirconia is an insulating material, a carbon layer was deposited on the sample surface to avoid charge accumulation during SEM observations. A Field Emission Gun - Scanning Electron Microscope (FEG-SEM Zeiss Merlin, Germany) was used for the imaging. The micrographs were acquired with a pixel size of $10 \mathrm{~nm}$ using the EverhartThornley Secondary Electron (SE) detector at an accelerating voltage of $3 \mathrm{kV}$.

Aside from the polished cross-section micrographs, all the pillars were also systematically observed after testing at low magnification by SEM in Secondary Electron (SE) mode (accelerating voltage of $3 \mathrm{kV}$ and working distance of $13 \mathrm{~mm}$ ). Besides, the internal damage was characterized for the specimen that were unloaded just before the final fracture. In this case, the cracks are expected to nucleate in in the upper part of the pillar (i.e. in a zone close to the top of the specimen) where the stresses are the highest. Therefore, $2 \mathrm{D}$ cross-sections localized in this zone of the tested pillars were polished using FIB-SEM (Crossbeam 540, Zeiss) at a milling current between 0.7-3 nA for the $\mathrm{Ga}^{+}$beam. A conducting $\mathrm{Au}$ layer was deposited on the top surface of the pillar to limit the charge accumulation and the beam shift during the abrasion. For practical reasons, it can be noticed that the impregnation of the microstructure by an epoxy resin is not possible in this specific case. The SEM images of the 2D FIB slices were acquired under conditions representative of 3-D imaging, i.e., acceleration voltages between 1.5-1.7 kV and current of 0.5-1.5 nA. Electron images from the secondary electrons Everhart-Thornley and in-lens energy-selective backscatterer were recorded for each region of interest. It can be noticed that the same procedure was applied to confirm that the microstructure of the YSZ skeleton was not affected by the dissolution of $\mathrm{Ni}$ in nitric acid, for the samples at high porosities before testing.

\subsubsection{Reconstructions by FIB-SEM and synchrotron X-ray holotomography}

The microstructure for all the investigated samples before testing were reconstructed for the accurate measurement of 3-D characteristic properties including the pore volume fraction. The 3D volumes were also used to verify the microstructure homogeneity of the tested materials. 
$3 D$ reconstructions by $F I B-S E M$ - For the pellets at intermediate porosities, the microstructural reconstructions were obtained by FIB-SEM (FEG-SEM NVISION 40, Carl ZEISS () slice and view. The porosities were previously filled by an epoxy resin to help the subsequent image segmentation. The energy selective backscatter (ESB) detector with a low acceleration voltage of $1.5 \mathrm{kV}$ was used for the electron images. Volumes of around $17^{3} \mu \mathrm{m}^{3}$ were acquired for the samples sintered at $1270^{\circ} \mathrm{C}, 1230^{\circ} \mathrm{C}, 1200^{\circ} \mathrm{C}$ and $1150^{\circ} \mathrm{C}$ with a voxel size of $10^{3} \mathrm{~nm}^{3}$.

The same procedure was also used to check that the milling procedure using pFIB for the micro-pillar preparation does not affect its microstructure. For this purpose, two 3D FIB-SEM (Zeiss Crossbeam 540, Atlas Fibics) reconstructions were obtained for the pellet sintered at $1270^{\circ} \mathrm{C}$ : the first one was acquired directly in one micro-pillar while the second one was taken just aside the well in which the specimen is centered ( $c f$. Fig. 6). Then, a set of microstructural properties was computed and a comparison between the results on the two 3D reconstructions was performed.

$3 D$ reconstructions by synchrotron X-ray holotomography - Regarding the highly porous samples, the mean diameter of the pore phase is significantly larger compared to the sintered pellets. Besides, the highly porous 8YSZ sample contains macro-pores (approx. 3 to $4 \mu \mathrm{m}$ in size). Therefore, to be representative of this type of microstructures, large reconstructed volumes, bigger than the one obtained by the FIB-SEM, are required [53]. For this purpose, the microstructure for the 3YSZ and 8YSZ highly porous samples were reconstructed at the Nano-Imaging Beamline (ID16A) of the European Synchrotron Radiation Facility (ESRF) using X-ray nano-holotomography [57,58]. Before proceeding to X-ray tomography, pillars of around $60 \mu \mathrm{m}$ in diameter were milled in the highly porous 8YSZ and 3YSZ pellets using pFIB (Fig. 2). Then, they were extracted using a micro-manipulator and fixed on a tip holder suitable for the $\mathrm{X}$-ray tomography measurements. Afterwards, two reconstructions of $51.2 \times \pi \times 25.6^{2} \mu \mathrm{m}^{3}$ were obtained for 8 YSZ and 3 YSZ with a voxel size of $25^{3} \mathrm{~nm}^{3}$.

\section{Results and discussions}

\subsection{Sample preparation}

\subsubsection{Porous pellets preparation}


The microstructure of porous 8YSZ pellets after partial sintering and after Ni dissolution was characterized by image analysis on SEM micrographs of polished cross-sections.

For the partially sintered pellets, the micrographs were taken in a region of interest close to the top surface of the pellets, where the micro-pillars are milled. As shown in Fig. 3a-d, SEM observations reveal that the microstructures of these samples are homogeneous with a rather uniform distribution of pores. When the sintering temperature is lowered from $1270^{\circ} \mathrm{C}$ to $1150^{\circ} \mathrm{C}$, the porosity fraction is increased with a significant decrease in the $2 \mathrm{D}$ connectivity of the solid phase at the lowest temperature (Fig. 3d). It can be pointed out that pellets sintered below a temperature of $1150^{\circ} \mathrm{C}$ showed no cohesion indicating a complete loss of the macroscopic percolation for the solid phase. It has been also checked that the microstructure remains homogeneous over a depth of about $200 \mu \mathrm{m}$ from the top surface to the bulk of the pellets. This dimension exceeds the typical height of the pillars (i.e. $\approx 130 \mu \mathrm{m})$ meaning that there is no porosity gradient in the volume of the tested specimen. Nevertheless, a decrease in the porosity was detected at longer range, going from the top surface to the center of the pellet. As an illustration, for the sample sintered at $1270^{\circ} \mathrm{C}$, the porosity measured at the pellet surface was $33 \%$ while the global estimation based on Archimedes principle has provided a porosity of $26 \%$. As a result, the manufacturing process adopted to produce porous 8YSZ pellets would not be appropriate for compression testing at macroscopic scale. Finally, the surface quality of the sintered pellets was also checked using optical microscopy. It has been found that after the mechanical polishing, the pellets are flat with a very slight residual roughness on the upper surface. It can be thus claimed that the protocol including the choice of the sintering temperatures and polishing conditions is validated for the preparation of the 8 YSZ pellets at intermediate porosities $(<50 \%)$.

SEM observations of the highly porous 8YSZ sample (Fig. 3e) after Ni dissolution have revealed a rather heterogeneous microstructure with some large pores randomly distributed in the volume. The presence of these macro-pores is explained by the use of a pore-forming agent during the manufacturing. It must be pointed out that a special attention was paid to optimize the Ni dissolution procedure in order to avoid YSZ surface decomposition by the nitric acid attack. For instance, as shown in Fig. 4a, defects such as holes at the surface of the 8YSZ skeleton were detected on a FIB-SEM cross section of a non-impregnated sample treated in nitric acid three times for $4 \mathrm{~h}$ under accelerated conditions using a magnetic stirrer 
(Fig. 4a). The improved procedure, which repeats the treatment in the nitric acid solution only twice without stirrer ( $c f$. section 2.1.2) allowed to dissolve the Ni by preserving the 8YSZ surface as shown in Fig. 4b. Then, the same protocol was used to obtain the highly porous 3YSZ sample. Its microstructure was also checked after the Ni dissolution. As for 8YSZ, the microstructure of the 3YSZ skeleton was preserved after Ni dissolution.

The 3D reconstructions of the pellets at intermediate and high porosities are displayed in Fig. 5. As shown in Fig. 5a-b, the microstructures of the partially sintered pellets are homogeneous with an increase in the solid phase size when densifying the sample. For highly porous specimens (Fig. 5c-d), the 3D reconstructions have confirmed that the Ni dissolution did not affect the YSZ skeleton. All these visual inspections of 3D volumes confirm the conclusions deduced from the $2 \mathrm{D}$ observations.

\subsubsection{Microstructural stability upon pFIB pillar milling}

As mentioned in section 2.3.2, the impact of the pFIB milling on the microstructural properties was assessed considering two 3D reconstructions, one taken in the pillar and the second one in a region close to the well in which the specimen is centered (for the pellet sintered at $1270^{\circ} \mathrm{C}$ : $c f$. Fig. 6). For this purpose, the tortuosity factor as well as the specific area for solid phase were computed using a set of programs detailed in the work of Moussaoui et al. [59]. It has been found that the tortuosity factor of the solid phase remains almost unchanged, being equal to 1.349 and 1.389 in the pellet and in the pillar after milling, respectively. For the solid phase specific surface area, only a very slight variation was detected between two volumes, which is more probably due to local variations in the microstructural properties (i.e. solid phase specific surface area is equal to $6.85 \mu \mathrm{m}^{-1}$ and 6.51 $\mu \mathrm{m}^{-1}$ before and after the milling). The absence of cracks in the material was also checked after milling. These results show that the microstructure is not affected by the pillar preparation and are in good agreement with the literature. Indeed, it has been shown in [49] that Xe ion implantation is limited to a few nanometers from the external surface and does not induce any damage in the bulk of the etched sample. As a result, the preparation of the pillar by $\mathrm{pFIB}$ is validated for the mechanical testing. It is worth noting that the methodology described in the present work could be adopted to prepare micro-pillars made of other porous ceramics. 


\subsection{Microstructural properties: pore volume fraction and phase size distribution}

The porosity fraction was initially estimated on segmented 2D SEM images. For this purpose, several SEM micrographs were taken for each type of pellet. The porosity estimation was further confirmed by measuring the property on the 3D reconstructions (Table 1). This pore volume fraction was directly given by the percentage of voxels associated to the porous phase. On the one hand, it has been found that the porosity varies from $33 \pm 1 \%$ to $49 \pm 1 \%$ when decreasing the sintering temperature from $1270^{\circ} \mathrm{C}$ to $1150^{\circ} \mathrm{C}$ for the $8 \mathrm{YSZ}$ partially sintered materials. On the other hand, a same porosity equal to $63 \pm 3 \%$ was measured on the both 3 YSZ and 8YSZ cermet substrates obtained after Ni dissolution. It can be noticed that the slight uncertainty in the measurements of the local porosity is mainly related to the image segmentation step. For example, the operations of erosion and dilatation by a voxel (or a pixel) in 3D (or 2D) segmentation of the investigated microstructures leads to a noticeable variation in the porosity measurement.

As expected, the comparison between the investigated microstructures showed that the highly porous samples obtained from SOC cermet supports are more heterogeneous than the partially sintered ones (Fig. 5). It can be also seen that the porosity size of the highly porous 8YSZ sample is significantly larger than in the other samples due to the use of pore former (Fig. $5 \mathrm{~d}$ ).

In order to quantify the difference between the investigated samples, a set of microstructural properties was assessed on 3D reconstructions. The continuous phase size distribution (PSD, i.e. the granulometry curves) was computed using morphological openings as described in $[59,60]$. The mean phase diameter, which corresponds to the particle size associated to $50 \%$ of the cumulative phase size distribution, was also determined from the granulometry curve.

For this purpose, volumes of $5^{3} \mu \mathrm{m}^{3}$ were used in the case of partially sintered samples. For the sake of clarity, the solid and porous phase size distributions are shown in Fig. 7a only for the 8YSZ samples sintered at the highest and the lowest temperatures (i.e. $\mathrm{T}=1270^{\circ} \mathrm{C}$ and $\mathrm{T}=1150^{\circ} \mathrm{C}$ ). The comparison between the two granulometry curves shows a similar shape. Nevertheless, the microstructure sintered at $1270^{\circ} \mathrm{C}$ is characterized by wider size distributions for the two phases as compared to the ones sintered at $1150^{\circ} \mathrm{C}$. Moreover, as expected, the size of the solid phase increases with increasing the sintering temperature due to the coarsening of the microstructure. Therefore, the size of 8YSZ phase is larger when the sintering temperature is higher with a significant increase in the mean particle size (i.e. solid phase mean diameter equal to $0.23 \mu \mathrm{m}$ and $0.09 \mu \mathrm{m}$ for the samples sintered at $1270^{\circ} \mathrm{C}$ and 
$1150^{\circ} \mathrm{C}$, respectively as reported in Table 1$)$. The porous phase mean diameter was found equal to $0.13 \mu \mathrm{m}$ and $0.09 \mu \mathrm{m}$ for the samples sintered at $1270^{\circ} \mathrm{C}$ and $1150^{\circ} \mathrm{C}$, respectively.

Regarding the highly porous 8YSZ sample, the microstructural properties have been calculated considering a larger volume of $25^{3} \mu \mathrm{m}^{3}$ as the sample contains larger local heterogeneities. As shown in Fig. 7b, the granulometry plot for the solid phase exhibits a nearly symmetric distribution around a mean value while a significant dissymmetry is observed in the distribution of the porous phase. This special feature in the PSD for the porous phase is related to the presence of a large number of macro-pores in the investigated microstructure. Moreover, the pore mean diameter, equal to $0.99 \mu \mathrm{m}$, is considerably larger than the ones measured for the partially sintered 8YSZ samples at intermediate porosities. This difference is mainly due to the use of pore former during the manufacturing and the $\mathrm{Ni}$ phase, which was removed from the sample. It can also be noticed that the solid phase size presents a wide distribution with a solid phase mean diameter equal to $0.62 \mu \mathrm{m}$ (Table 1).

For the highly porous 3 YSZ sample, the phase size distribution was computed considering a volume of $15^{3} \mu \mathrm{m}^{3}$ adapted to the size of the heterogeneities in this microstructure (Fig. $5 \mathrm{c}$, 7c). It can be seen that the PSD plot for the porous phase has an almost symmetric shape. A slight dissymmetry in the curve can be noticed for the highest values of particle diameter illustrating a rather limited heterogeneity of the microstructure. A mean pore diameter of 0.33 $\mu \mathrm{m}$ is found for this 3 YSZ sample. This value is much lower than the one of the 8 YSZ sample although the same pore volume fraction is maintained. This result is explained by the macropores present in the highly porous 8YSZ sample, generated by pore-forming agents. Finally, it can be noted that the solid phase mean diameter for the highly porous 3YSZ sample, equal to $0.25 \mu \mathrm{m}$, is in the same range as the one computed on the $8 \mathrm{YSZ}$ sample sintered at $1270^{\circ} \mathrm{C}$ (i.e. $0.23 \mu \mathrm{m})($ Table 1$)$.

To conclude, 8YSZ samples with a wide range of porosities from $33 \%$ to $63 \%$ were obtained allowing to test the influence of porosity fraction on the compression fracture strength. The volume fraction and PSD calculations let anticipate meaningful comparison of the mechanical behavior of highly porous 8YSZ and 3YSZ, despite the slight differences in their microstructures.

\subsection{Micro-compression testing results}


Two series of micro-compression tests were conducted on porous YSZ pillars under monotonic loading, just before specimen fracture and up to specimen collapse ( $c f$. section 2.2). The load-displacement response of each type of sample in the first series is displayed in Fig. 8. It can be noticed that the behavior during loading is not perfectly linear especially at low displacements. During this initial stage, the pillar presents a low apparent stiffness that must be explained by the progressive setting of the contact between the specimen and the flat punch indenter. Indeed, as discussed in [34], this first non-linear step can be ascribed to the compression of the surface defects on the top of the pillars such as roughness or possible presence of some debris. It can be mentioned that this explanation is consistent with the fact that this non-linear behavior was found to be much larger on preliminary tests when the surface of the pellets were not carefully polished according to the procedure described in section 2.1.1. This result highlights the crucial role of the surface preparation for the microcompression testing.

This first nonlinear stage in the load-displacement curve is then followed by an almost linear response once the contact between the flat punch and the sample surface is established (Fig. 8a-e). It is to be noted that, in contrast to other samples, the force-displacement curve for the highly porous 8 YSZ pillar presents some perturbations with small steps at constant load all along the loading (Fig. 8f). This noise on the data is related to the very low force measured for this specific sample (the force is lower than $40 \mathrm{mN}$ ).

The Young's moduli of the porous 8YSZ pillars were estimated from the initial slope of the unloading curves. For this purpose, finite element simulations of the compression test were conducted assuming a pure elastic behavior with a Poisson's ratio fixed to 0.31 [61]. For this modeling, a 2D approach including the full geometry of the tapered pillar attached to a part of the pellet was adopted using axisymmetric conditions. The size of the simulated pellet substrate was chosen in such a way that the mechanical response of the pillar becomes independent of boundary conditions applied at the bottom of the substrate (i.e. the displacements are blocked in the axial direction). As in the experiments, the imposed displacements were applied at the top of the pillar assuming a perfect sliding between the specimen and the flat punch. For these specific experiments (i.e. sample size and loading), it has been checked that the potential friction between the $8 \mathrm{YSZ}$ and the indenter does not change significantly the pillar mechanical response. This modeling has allowed identifying the Young's modulus by fitting the experimental data recorded during the early stage of the specimen unloading (Table 2). For each type of porous pillar, the mean slope from three tests 
was considered to take into account the scattering in the experimental measurements for the Young's modulus estimation. It must be noticed that the unloading curve was used as it is affected neither by the initial establishment of the contact nor by the small perturbations as noted in the loading curve.

The Young's modulus estimated by FE simulations of the experiments is plotted as a function of the 8YSZ porosity in Fig. 9. As expected, the Young's modulus E is found to be significantly decreased with increasing the porosity $\mathrm{p}$. Moreover, the experimental data have been compared to the prediction of the so-called modified-exponential model (i.e. $\mathrm{E}=$ $\left.\mathrm{E}_{0} \exp ^{\left(\frac{-[\mathrm{E}] \mathrm{p}}{1-\mathrm{p}}\right)}[62]\right)$, proposed for porous ceramics, considering a Young's modulus for dense $8 \mathrm{YSZ}_{0}$ of $216 \mathrm{GPa}$ [61] and an intrinsic elastic modulus [E] of 2.2 [62]. Without any fitting, it can be seen that the modified-exponential law is roughly in good agreement with the measurements (Fig. 9). Therefore, even if these experiments were mainly designed to study the fracture behavior of porous ceramics considering micro-samples, satisfactory estimation of the Young's modulus can also be made from the unloading curve of unbroken samples.

The second series of experiments were conducted on other pillars until their total collapse. Considering the initial geometry of the pillar (i.e. total height and top surface diameter), engineering stress-strain data were calculated from the recorded load-displacement measurements. Examples of the typical stress-strain curves plotted until fracture are presented in Fig. 10. As it can be seen in Fig. 10a-d, the fracture occurs suddenly for the pillars with porosity ranging from $33 \%$ to $49 \%$. No signs of internal damage are detected in the mechanical response before the total fracture, suggesting a pure brittle behavior of the 8YSZ ceramic at intermediate porosities. In Fig. 10e-f, for the highly porous samples, a slight deviation in the slope just before failure is observed in the loading curve. This specific mechanical response obtained at the highest porosity (i.e. 63\%) could be an indicator of an internal damage starting before the total fracture. This observation could thus suggest a change in the material fracture mode under uniaxial compression at high porosity.

For each investigated porosity and material, at least five pillars were tested to identify the compressive fracture strength and quantify the dispersion in the measurements. It is to be noted that the compressive fracture strength corresponds to the maximum strength measured just before the pillar collapse, marked by a star in Fig. 10. As reported in Table 2, the standard deviation for the measured fracture strength does not exceed a few percent of the mean value. This is a rather low data scattering for local measurements on micro porous samples. The 
evolution of the measured fracture strength is plotted as a function of the porosity in Fig. 11 for the $8 \mathrm{YSZ}$ samples. It can be remarked that the compressive fracture strength is strongly decreased with increasing the porosity. Indeed, the fracture strength is divided by a factor of 58 when the porosity is increased from $33 \%$ to $63 \%$. This evolution of the experimental data is well fitted by a power law equation as shown in Fig. 10. This result is in good agreement with the strength-porosity dependence relations proposed in literature from macro-scale measurements $[63,64]$.

Finally, the fracture strength measured for the highly porous 3YSZ is found considerably higher than for $8 \mathrm{YSZ}$ at similar porosity. This difference is mainly due to the intrinsic fracture properties of each material, known to be larger in 3YSZ [13,65], as well as most probably the noticeable differences in microstructures (with the presence of macro-pores in the highly porous 8YSZ sample).

\subsection{Post-mortem characterizations}

Pillars tested and unloaded before total fracture (first series of tests) were cross-sectioned and observed using FIB-SEM. Only the tests stopped at a loading slightly below the compressive fracture strength were selected to visualize the potential micro-cracks created in the pillars before their collapse. Since the transition from a damaged ceramic material to its totally broken state is very fast during our strain-controlled experiments, several calibration tests were required to be able to stop the loading just before the fracture. The resulting cracks within the $8 \mathrm{YSZ}$ sample sintered at $1270^{\circ} \mathrm{C}$ and the highly porous $8 \mathrm{YSZ}$ and $3 \mathrm{YSZ}$ specimens are shown in Fig. 12-13.

As it can be seen in Fig. $12 \mathrm{a}-\mathrm{c}$ for the lowest porosity (i.e. sample sintered at $1270^{\circ} \mathrm{C}$ ), a large crack parallel to the loading direction is observed in the pillar before the total collapse (first series of experiments). The same fracture mode with very few large cracks parallel to the loading direction was observed for the samples sintered at $1230^{\circ} \mathrm{C}, 1200^{\circ} \mathrm{C}$ and $1150^{\circ} \mathrm{C}$. Therefore, the 8 YSZ material with porosities ranging from $33 \%$ to $49 \%$ is characterized by a brittle behavior as anticipated from the mechanical response during compression ( $c f$. section 3.3). These observations are in good agreement with the theoretical study [66] as well as with experimental results obtained on macro-samples of porous alumina [67]. 
According to the brittle behavior at intermediate porosity, the fracture onset must be controlled by the weakest local zones in the microstructure from which a large crack nucleates and propagates to the whole specimen. In porous materials subjected to compression, critical sites for cracks initiation are likely to be related to local microstructure characteristics (pore size, orientation, ligament between two pores, etc.), leading to high local tensile stresses within the solid phase. The fracture triggers from one of these sites and then extends to the whole specimen [68]. Interestingly, despite the sensitivity of the compressive fracture strength to the first large crack nucleation, the experimental results were reproducible with a relative low scattering of the measurements. This could be explained by the homogeneity of the microstructure in the micro-pillar for the partially-sintered pellets with intermediate porosities.

In contrast to the intermediate porosity case, the post-mortem characterizations of the highly porous 8 YSZ pillars have revealed a distribution of micro-cracks in the microstructure. As shown in Fig. 13a, the density of these micro-cracks is maximal in the upper part of the pillar where the compression is the highest (because of the tapered shape of the pillar as discussed in section 2.1.3). These observations clearly indicate a different mechanism of fracture from the one at intermediate porosities. Indeed, for the highly porous sample, a local damage is induced in the material before the total fracture of the specimen. This internal damage explains the non-linear response, which is observed on the stress-strain response before the pillar fracture (Fig. 10f). It is worth noting that this result is in good agreement with the work of Meille et al. dedicated to highly porous alumina samples tested in compression at macroscopic scale [67]. Indeed, as shown in Fig. 13a, the authors had also observed a distribution of micro-cracks related to the local fracture of the solid walls between pores. The generation of these stable micro-cracks is also linked to local concentration of high tensile stresses in the solid phase. Then, the diffuse damage within the microstructure progressively increases until the final fracture of the material. Because of this damageable fracture mode, the fracture strength in compression should not be controlled by the first crack initiation event. Therefore, since the total fracture is not sensitive to the weakest zone in the microstructure, the limited dispersion of the compressive fracture strength measurements must be mainly ascribed to the specific fracture mechanism based on progressive damage upon loading. A similar damage behavior has been also noted for the highly porous 3 YSZ sample. Indeed, as shown in (Fig. 13b), a network of micro-cracks between pores are also observed in the upper part of the specimen. As for the highly porous 8YSZ, this internal damage arising 
before the total fracture is consistent with the non-linear response of the stress-strain curve (Fig. 10e). Therefore, despite the difference in mechanical properties with 8YSZ, the fracture mechanism of the highly porous $3 \mathrm{YSZ}$ is also governed by the generation of stable microcracks in the microstructure.

A transition in the fracture mode has been highlighted from a brittle behavior with large cracks at porosities below 50\%, towards local damaging with micro-cracks at high porosity, similarly to the one observed on porous alumina on macro-samples [67]. This change in mechanism could be controlled by the stored elastic energy, which decreases with increasing the pore volume fraction. A larger amount of available elastic energy favors the instable propagation of long cracks as noted at intermediate porosities. Nevertheless, further studies are still required to better understand this transition. From this point of view, the mechanical modeling of the 3D microstructure could be a relevant tool to analyze the fracture behavior of these porous ceramics [68].

\subsection{Sample size effect}

The compressive fracture strength measured in the present work on 8YSZ micro-pillars at a porosity of $63 \%$ (i.e. $25 \pm 3 \mathrm{MPa}$ ) is in good agreement with the data available in the literature obtained on macroscopic samples of $8 \mathrm{YSZ}$ at a porosity of $65 \%$ (i.e. $27 \mathrm{MPa}$ ) [31,32]. It can be thus deduced that the compressive fracture properties for the highly porous 8YSZ do not depend on the size of the tested specimen. The uniaxial compressive loading and the high porosity fraction could explain this statement. Indeed, at this porosity level, a local damage by the creation of micro-cracks is observed under compression. Solid walls between pores subjected to the highest tensile stress are broken first. Due to the low stored elastic energy, the fracture remains local and does not lead to the propagation of large cracks. The diffuse damage within the microstructure then progressively increases up to the density threshold leading to the total collapse of the material. In other words, at high porosity, the compressive fracture strength level is controlled by the density of the micro-cracks created in the specimen thus explaining the absence of a sample size effect as noted in this work.

On the other hand, when the fracture mechanism is controlled by a pure brittle behavior at intermediate porosities, the available data at the macroscopic scale is not yet sufficient to discuss the sample size effect on the compressive fracture strength. Therefore, further investigations at porosities below $50 \%$ are still required. 


\section{Conclusion}

A protocol has been proposed in the present work for the testing of porous ceramics with microstructures averaging the contribution of porous and solid phases in 10-100 $\mu \mathrm{m}$ length scale, starting from micro-compression specimen fabrication and testing up to post-mortem characterizations. This original methodology has been applied to measure the fracture properties of porous Yttria-Stabilized Zirconia tested under micro-compression. The specimen for the experiments were prepared using $\mathrm{Xe}^{+} \mathrm{pFIB}$, which enabled to mill into porous YSZ pellets suitable micro-pillars with a typical diameter of $60 \mu \mathrm{m}$. The homogeneity of the porous microstructures was estimated by measuring relevant microstructural characteristics on cross-sections and 3D reconstructions obtained by electron and X-ray microscopy.

The Young's modulus was estimated from the unloading curves of pillars tested before failure and the compressive fracture strength was measured on pillars tested until the total fracture. These properties were determined for the 8 YSZ material over a large range of porosities (33\% to $63 \%$ ) and for the $3 \mathrm{YSZ}$ ceramic at high porosity (63\%). All the experiments were reproducible with a rather limited data scattering. A substantial decrease was found for the compressive fracture strength when increasing the porosity. Pillars tested and unloaded just before total failure were also cross-sectioned by FIB-SEM to support the analysis of mechanical failure behavior. A transition from a brittle behavior to a damage fracture mode was highlighted when increasing the porosity. Indeed, large cracks parallel to the direction of solicitation were observed at porosities below 50\% while diffuse damage with micro-cracks was detected within the highly porous 3 YSZ and 8 YSZ samples at $63 \%$.

\section{Acknowledgements}

This project has received funding from the Fuel Cells and Hydrogen 2 Joint Undertaking (JU) under grant agreement $n^{\circ} 825027$ (AD ASTRA project). The JU receives support from the European Union's Horizon 2020 research and innovation program and Denmark, France, Italy, Spain, Poland, Netherlands, Greece, Finland, Estonia, Germany, United Kingdom, Switzerland. The work has also been partially supported by the Carnot Institutes (CASSIOPEE project) and Genvia company. The authors acknowledge access to the 
nanocharacterization plat-form (PFNC) at the Minatec Campus in Grenoble and thank Guillaume Audoit for his invaluable help in the preparation of micro-pillars. 


\section{References}

[1] T. Goto, A New Thick Film Coating Technology-Laser Chemical Vapor Deposition, in: Handbook of Advanced Ceramics, Elsevier, 2013: pp. 837-846. https://doi.org/10.1016/B978-0-12-385469-8.00045-9.

[2] E.C. Hammel, O.L.-R. Ighodaro, O.I. Okoli, Processing and properties of advanced porous ceramics: An application based review, Ceramics International. 40 (2014) 15351-15370. https://doi.org/10.1016/j.ceramint.2014.06.095.

[3] Y. Ito, Heat-Resistant Coating Technology for Gas Turbines, in: Handbook of Advanced Ceramics, Elsevier, 2013: pp. 789-806. https://doi.org/10.1016/B978-0-12-3854698.00043-5.

[4] Y. Kawahara, Application of High-Temperature Corrosion-Resistant Ceramics and Coatings under Aggressive Corrosion Environment in Waste-To-Energy Boilers, in: Handbook of Advanced Ceramics, Elsevier, 2013: pp. 807-836. https://doi.org/10.1016/B978-0-12-385469-8.00044-7.

[5] P.S. Liu, G.F. Chen, Applications of Porous Ceramics, in: Porous Materials, Elsevier, 2014: pp. 303-344. https://doi.org/10.1016/B978-0-12-407788-1.00006-X.

[6] U.M.B. Al-Naib, Introductory Chapter: A Brief Introduction to Porous Ceramic, in: U.M.B. Al-Naib (Ed.), Recent Advances in Porous Ceramics, InTech, 2018. https://doi.org/10.5772/intechopen.74747.

[7] P.S. Liu, G.F. Chen, General Introduction to Porous Materials, in: Porous Materials, Elsevier, 2014: pp. 1-20. https://doi.org/10.1016/B978-0-12-407788-1.00001-0.

[8] T. Ohji, Porous Ceramic Materials, in: Handbook of Advanced Ceramics, Elsevier, 2013: pp. 1131-1148. https://doi.org/10.1016/B978-0-12-385469-8.00059-9.

[9] S. Gopi, A. Pius, S. Thomas, Synthesis, microstructure, and properties of high-strength porous ceramics, in: Fundamental Biomaterials: Ceramics, Elsevier, 2018: pp. 265-271. https://doi.org/10.1016/B978-0-08-102203-0.00011-1.

[10] T. Ohji, Microstructural Control and Mechanical Properties, in: Handbook of Advanced Ceramics, Elsevier, 2013: pp. 657-673. https://doi.org/10.1016/B978-0-12-3854698.00035-6.

[11] S.C. Singhal, K. Kendall, High Temperature Solid Oxide Fuel Cells, Fundamentals, Design and Applications, Elsevier, 360 Park Avenue South, New York, NY 10010-1710, USA, 2003.

[12] B. Zhu, Advantages of intermediate temperature solid oxide fuel cells for tractionary applications, Journal of Power Sources. 93 (2001) 82-86. https://doi.org/10.1016/S03787753(00)00564-4.

[13] M. Ghatee, M.H. Shariat, J.T.S. Irvine, Investigation of electrical and mechanical properties of 3YSZ/8YSZ composite electrolytes, Solid State Ionics. (2009) 6.

[14] C. Suciu, Physico-chemical properties of nanocrystalline YSZ powders as a function of doping level and electrical properties after sintering, (2018) 10.

[15] S.P. Jiang, S.H. Chan, A review of anode materials development in solid oxide fuel cells, Journal of Materials Science. 39 (2004) 4405-4439. https://doi.org/10.1023/B:JMSC.0000034135.52164.6b.

[16] N.H. Menzler, F. Tietz, S. Uhlenbruck, H.P. Buchkremer, D. Stöver, Materials and manufacturing technologies for solid oxide fuel cells, J Mater Sci. 45 (2010) 3109-3135. https://doi.org/10.1007/s10853-010-4279-9.

[17] E. Lay-Grindler, J. Laurencin, G. Delette, J. Aicart, M. Petitjean, L. Dessemond, Micro modelling of solid oxide electrolysis cell: From performance to durability, International Journal of Hydrogen Energy. 38 (2013) 6917-6929. https://doi.org/10.1016/j.ijhydene.2013.03.162. 
[18] Y. Hsiao, The degradation of SOFC electrodes, Solid State Ionics. 98 (1997) 33-38. https://doi.org/10.1016/S0167-2738(97)00106-9.

[19] L. Liu, G.-Y. Kim, A. Chandra, Modeling of thermal stresses and lifetime prediction of planar solid oxide fuel cell under thermal cycling conditions, Journal of Power Sources. (2010) 9.

[20] J.B. Robinson, L.D. Brown, R. Jervis, O.O. Taiwo, T.M.M. Heenan, J. Millichamp, T.J. Mason, T.P. Neville, R. Clague, D.S. Eastwood, C. Reinhard, P.D. Lee, D.J.L. Brett, P.R. Shearing, Investigating the effect of thermal gradients on stress in solid oxide fuel cell anodes using combined synchrotron radiation and thermal imaging, Journal of Power Sources. 288 (2015) 473-481. https://doi.org/10.1016/j.jpowsour.2015.04.104.

[21] H. Yokokawa, H. Tu, B. Iwanschitz, A. Mai, Fundamental mechanisms limiting solid oxide fuel cell durability, Journal of Power Sources. (2008) 13.

[22] S. Sukino, S. Watanabe, K. Sato, F. Iguchi, H. Yugami, T. Kawada, J. Mizusaki, T. Hashida, Effect of Redox Cycling on Mechanical Properties of Ni-YSZ Cermets for SOFC Anodes, ECS Trans. 35 (2019) 1473-1482. https://doi.org/10.1149/1.3570133.

[23] A. Faes, A. Nakajo, A. Hessler-Wyser, D. Dubois, A. Brisse, S. Modena, J. Van herle, RedOx study of anode-supported solid oxide fuel cell, Journal of Power Sources. 193 (2009) 55-64. https://doi.org/10.1016/j.jpowsour.2008.12.118.

[24] T. Klemensø, C. Chung, P.H. Larsen, M. Mogensen, The Mechanism Behind Redox Instability of Anodes in High-Temperature SOFCs, Journal of The Electrochemical Society. (n.d.) 8.

[25] A. Nakajo, A.M. Kiss, A.P. Cocco, W.M. Harris, M.B. DeGostin, F. Greco, G.J. Nelson, A.A. Peracchio, B.N. Cassenti, A. Deriy, S. Wang, Y. Chen-Wiegart, J. Wang, J. Van herle, W.K.S. Chiu, Characterization of Cracks and their Effects on the Effective Transport Pathways in Ni-YSZ Anodes after Reoxidation Using X-Ray Nanotomography, ECS Transactions. 68 (2015) 1069-1081. https://doi.org/10.1149/06801.1069ecst.

[26] A. Faes, A. Hessler-Wyser, A. Zryd, J. Van herle, A Review of RedOx Cycling of Solid Oxide Fuel Cells Anode, Membranes. 2 (2012) 585-664. https://doi.org/10.3390/membranes2030585.

[27] D. Sarantaridis, R.A. Rudkin, A. Atkinson, Oxidation failure modes of anode-supported solid oxide fuel cells, Journal of Power Sources. (2008) 7.

[28] J. Laurencin, V. Roche, C. Jaboutian, I. Kieffer, J. Mougin, M.C. Steil, Ni-8YSZ cermet re-oxidation of anode supported solid oxide fuel cell: From kinetics measurements to mechanical damage prediction, International Journal of Hydrogen Energy. 37 (2012) 12557-12573. https://doi.org/10.1016/j.ijhydene.2012.06.019.

[29] J. Laurencin, G. Delette, B. Morel, F. Lefebvre-Joud, M. Dupeux, Solid Oxide Fuel Cells damage mechanisms due to Ni-YSZ re-oxidation: Case of the Anode Supported Cell, Journal of Power Sources. 192 (2009) 344-352. https://doi.org/10.1016/j.jpowsour.2009.02.089.

[30] P. Khajavi, J. Chevalier, P. Vang Hendriksen, J.W. Tavacoli, L. Gremillard, H. Lund Frandsen, Double Torsion testing of thin porous zirconia supports for energy applications: Toughness and slow crack growth assessment, Journal of the European Ceramic Society. 40 (2020) 3191-3199. https://doi.org/10.1016/j.jeurceramsoc.2020.02.019.

[31] L. Hu, C.-A. Wang, Effect of sintering temperature on compressive strength of porous yttria-stabilized zirconia ceramics, Ceramics International. 36 (2010) 1697-1701. https://doi.org/10.1016/j.ceramint.2010.03.009. 
[32] Y. Dong, C.-A. Wang, J. Zhou, Effect of YSZ fiber addition on microstructure and properties of porous YSZ ceramics, Journal of Materials Science. 47 (2012) 6326-6332. https://doi.org/10.1007/s10853-012-6555-3.

[33] M. Ettler, H. Timmermann, J. Malzbender, A. Weber, N.H. Menzler, Durability of Ni anodes during reoxidation cycles, Journal of Power Sources. 195 (2010) 5452-5467. https://doi.org/10.1016/j.jpowsour.2010.03.049.

[34] E. Camposilvan, M. Anglada, Size and plasticity effects in zirconia micropillars compression, Acta Materialia. 103 (2016) 882-892. https://doi.org/10.1016/j.actamat.2015.10.047.

[35] M. Mutoh, T. Nagoshi, T.-F. Mark Chang, T. Sato, M. Sone, Micro-compression test using non-tapered micro-pillar of electrodeposited $\mathrm{Cu}$, Microelectronic Engineering. 111 (2013) 118-121. https://doi.org/10.1016/j.mee.2013.02.040.

[36] H. Tang, K. Hashigata, T.-F.M. Chang, C.-Y. Chen, T. Nagoshi, D. Yamane, T. Konishi, K. Machida, K. Masu, M. Sone, Sample size effect on micro-mechanical properties of gold electroplated with dense carbon dioxide, Surface and Coatings Technology. 350 (2018) 1065-1070. https://doi.org/10.1016/j.surfcoat.2018.02.041.

[37] T. Nagoshi, T.-F.M. Chang, S. Tatsuo, M. Sone, Mechanical properties of nickel fabricated by electroplating with supercritical $\mathrm{CO} 2$ emulsion evaluated by microcompression test using non-tapered micro-sized pillar, Microelectronic Engineering. 110 (2013) 270-273. https://doi.org/10.1016/j.mee.2013.02.001.

[38] J.R. Greer, W.C. Oliver, W.D. Nix, Size dependence of mechanical properties of gold at the micron scale in the absence of strain gradients, Acta Materialia. 53 (2005) 18211830. https://doi.org/10.1016/j.actamat.2004.12.031.

[39] Y. Yang, J.C. Ye, J. Lu, F.X. Liu, P.K. Liaw, Effects of specimen geometry and base material on the mechanical behavior of focused-ion-beam-fabricated metallic-glass micropillars, Acta Materialia. 57 (2009) 1613-1623. https://doi.org/10.1016/j.actamat.2008.11.043.

[40] Y. Xiao, V. Maier-Kiener, J. Michler, R. Spolenak, J.M. Wheeler, Deformation behavior of aluminum pillars produced by Xe and Ga focused ion beams: Insights from strain rate jump tests, Materials \& Design. 181 (2019) 107914. https://doi.org/10.1016/j.matdes.2019.107914.

[41] R. Henry, T. Blay, T. Douillard, A. Descamps-Mandine, I. Zacharie-Aubrun, J.-M. Gatt, C. Langlois, S. Meille, Local fracture toughness measurements in polycrystalline cubic zirconia using micro-cantilever bending tests, Mechanics of Materials. 136 (2019) 103086. https://doi.org/10.1016/j.mechmat.2019.103086.

[42] W. Luo, C. Kirchlechner, X. Fang, S. Brinckmann, G. Dehm, F. Stein, Influence of composition and crystal structure on the fracture toughness of $\mathrm{NbCo} 2$ Laves phase studied by micro-cantilever bending tests, Materials \& Design. 145 (2018) 116-121. https://doi.org/10.1016/j.matdes.2018.02.045.

[43] D. Gonzalez-Nino, S. Sonntag, M. Afshar-Mohajer, J. Goss, M. Zou, G.S. Prinz, Micromechanical Tension Testing of Additively Manufactured 17-4 PH Stainless Steel Specimens, JoVE (Journal of Visualized Experiments). (2021) e62433. https://doi.org/10.3791/62433.

[44] J.M. Tarragó, J.J. Roa, E. Jiménez-Piqué, E. Keown, J. Fair, L. Llanes, Mechanical deformation of WC-Co composite micropillars under uniaxial compression, International Journal of Refractory Metals and Hard Materials. 54 (2016) 70-74. https://doi.org/10.1016/j.ijrmhm.2015.07.015.

[45] X. Zhang, Q. Zhao, S. Wang, R. Trejo, E. Lara-Curzio, G. Du, Characterizing strength and fracture of wood cell wall through uniaxial micro-compression test, Composites Part 
A: Applied Science and Manufacturing. 41 (2010) 632-638.

https://doi.org/10.1016/j.compositesa.2010.01.010.

[46] Z. Du, X.M. Zeng, Q. Liu, A. Lai, S. Amini, A. Miserez, C.A. Schuh, C.L. Gan, Size effects and shape memory properties in $\mathrm{ZrO} 2$ ceramic micro- and nano-pillars, Scripta Materialia. 101 (2015) 40-43. https://doi.org/10.1016/j.scriptamat.2015.01.013.

[47] C. Chen, S. Nagao, T. Sugahara, H. Zhang, J. Jiu, K. Suganuma, T. Iwashige, K. Sugiura, K. Tsuruta, Effect of size and shape of Ag particles for mechanical properties of sintered Ag joints evaluated by micro-compression test, in: 2017 International Conference on Electronics Packaging (ICEP), IEEE, Yamagata, Japan, 2017: pp. 130 134. https://doi.org/10.23919/ICEP.2017.7939340.

[48] J. Laurencin, G. Delette, F. Usseglio-Viretta, S. Di Iorio, Creep behaviour of porous SOFC electrodes: Measurement and application to Ni-8YSZ cermets, Journal of the European Ceramic Society. 31 (2011) 1741-1752. https://doi.org/10.1016/j.jeurceramsoc.2011.02.036.

[49] A. Ernst, M. Wei, M. Aindow, A Comparison of Ga FIB and Xe-Plasma FIB of Complex Al Alloys, Microsc Microanal. 23 (2017) 288-289. https://doi.org/10.1017/S1431927617002124.

[50] R. Mahbub, T. Hsu, W.K. Epting, N.T. Nuhfer, G.A. Hackett, H. Abernathy, A.D. Rollett, M. De Graef, S. Litster, P.A. Salvador, A Method for Quantitative 3D Mesoscale Analysis of Solid Oxide Fuel Cell Microstructures Using Xe-plasma Focused Ion Beam (PFIB) Coupled with SEM, ECS Trans. 78 (2017) 2159-2170. https://doi.org/10.1149/07801.2159ecst.

[51] P.R. Munroe, The application of focused ion beam microscopy in the material sciences, MATERIALS CHARACTERIZATION. (2009) 12.

[52] C.A. Volkert, A.M. Minor, Focused Ion Beam Microscopy and Micromachining, MRS Bull. 32 (2007) 389-399. https://doi.org/10.1557/mrs2007.62.

[53] J. Laurencin, R. Quey, G. Delette, H. Suhonen, P. Cloetens, P. Bleuet, Characterisation of Solid Oxide Fuel Cell Ni-8YSZ substrate by synchrotron X-ray nano-tomography: from 3D reconstruction to microstructure quantification, Journal of Power Sources. 198 (2012) 182-189. https://doi.org/10.1016/j.jpowsour.2011.09.105.

[54] A.W. Colldeweih, A. Baris, P. Spätig, S. Abolhassani, Evaluation of mechanical properties of irradiated zirconium alloys in the vicinity of the metal-oxide interface, Materials Science and Engineering: A. 742 (2019) 842-850. https://doi.org/10.1016/j.msea.2018.09.107.

[55] H. Zhang, B.E. Schuster, Q. Wei, K.T. Ramesh, The design of accurate microcompression experiments, Scripta Materialia. 54 (2006) 181-186. https://doi.org/10.1016/j.scriptamat.2005.06.043.

[56] J.H. Fitschen, J. Ma, S. Schuff, Removal of curtaining effects by a variational model with directional forward differences, Computer Vision and Image Understanding. 155 (2017) 24-32. https://doi.org/10.1016/j.cviu.2016.12.008.

[57] J. Villanova, J. Laurencin, P. Cloetens, P. Bleuet, G. Delette, H. Suhonen, F. UsseglioViretta, 3D phase mapping of solid oxide fuel cell YSZ/Ni cermet at the nanoscale by holographic X-ray nanotomography, Journal of Power Sources. 243 (2013) 841-849. https://doi.org/10.1016/j.jpowsour.2013.06.069.

[58] M. Hubert, A. Pacureanu, C. Guilloud, Y. Yang, J.C. da Silva, J. Laurencin, F. LefebvreJoud, P. Cloetens, Efficient correction of wavefront inhomogeneities in X-ray holographic nanotomography by random sample displacement, Appl. Phys. Lett. 112 (2018) 203704. https://doi.org/10.1063/1.5026462. 
[59] H. Moussaoui, Microstructural optimization of Solid Oxide Cells: a coupled stochastic geometrical and electrochemical modeling approach applied to LSCF-CGO electrode, (2019) 193.

[60] H. Moussaoui, J. Laurencin, Y. Gavet, G. Delette, M. Hubert, P. Cloetens, T. Le Bihan, J. Debayle, Stochastic geometrical modeling of solid oxide cells electrodes validated on 3D reconstructions, Computational Materials Science. 143 (2018) 262-276. https://doi.org/10.1016/j.commatsci.2017.11.015.

[61] A. Selçuk, A. Atkinson, Strength and Toughness of Tape-Cast Yttria-Stabilized Zirconia, Journal of the American Ceramic Society. 83 (2004) 2029-2035. https://doi.org/10.1111/j.1151-2916.2000.tb01507.x.

[62] W. Pabst, E. Gregorová, G. Tichá, Elasticity of porous ceramics - A critical study of modulus-porosity relations, Journal of the European Ceramic Society. 26 (2006) 10851097. https://doi.org/10.1016/j.jeurceramsoc.2005.01.041.

[63] E. Ryshkewitch, Compression Strength of Porous Sintered Alumina and Zirconia.: 9th Communication to Ceramography, J American Ceramic Society. 36 (1953) 65-68. https://doi.org/10.1111/j.1151-2916.1953.tb12837.x.

[64] X. Chen, S. Wu, J. Zhou, Influence of porosity on compressive and tensile strength of cement mortar, Construction and Building Materials. 40 (2013) 869-874. https://doi.org/10.1016/j.conbuildmat.2012.11.072.

[65] D.N. Boccaccini, H.L. Frandsen, S. Soprani, M. Cannio, T. Klemens $\varnothing$, V. Gil, P.V. Hendriksen, Influence of porosity on mechanical properties of tetragonal stabilized zirconia, Journal of the European Ceramic Society. 38 (2018) 1720-1735. https://doi.org/10.1016/j.jeurceramsoc.2017.09.029.

[66] R. Romani, M. Bornert, D. Leguillon, R. Le Roy, K. Sab, Detection of crack onset in double cleavage drilled specimens of plaster under compression by digital image correlation - Theoretical predictions based on a coupled criterion, European Journal of Mechanics - A/Solids. 51 (2015) 172-182. https://doi.org/10.1016/j.euromechsol.2014.12.002.

[67] S. Meille, M. Lombardi, J. Chevalier, L. Montanaro, Mechanical properties of porous ceramics in compression: On the transition between elastic, brittle, and cellular behavior, Journal of the European Ceramic Society. 32 (2012) 3959-3967. https://doi.org/10.1016/j.jeurceramsoc.2012.05.006.

[68] A. Abaza, J. Laurencin, A. Nakajo, S. Meille, J. Debayle, D. Leguillon, Prediction of crack nucleation and propagation in porous ceramics using the phase-field approach, Under Submission. (2021). 
Table 1. Microstructural properties of the investigated samples computed on 3D reconstructions.

\begin{tabular}{|c|c|c|c|}
\hline Preparation method & $\begin{array}{c}\text { Pore volume } \\
\text { fraction } \\
{[\%]}\end{array}$ & $\begin{array}{c}\text { Solid phase mean } \\
\text { diameter } \\
{[\mu \mathrm{m}]}\end{array}$ & $\begin{array}{c}\text { Porous phase } \\
\text { mean diameter } \\
{[\mu \mathrm{m}]}\end{array}$ \\
\hline $\begin{array}{c}\text { Partial sintering at } 1270^{\circ} \mathrm{C} \text { for } \\
8 \mathrm{YSZ} \text { sample }\end{array}$ & $33 \pm 1$ & 0.23 & 0.13 \\
\hline $\begin{array}{c}\text { Partial sintering at } 1230^{\circ} \mathrm{C} \text { for } \\
8 \mathrm{YSZ} \text { sample }\end{array}$ & $36 \pm 1$ & - & - \\
\hline $\begin{array}{c}\text { Partial sintering at } 1200^{\circ} \mathrm{C} \text { for } \\
8 \mathrm{YSZ} \text { sample }\end{array}$ & $40 \pm 1$ & - & 0.09 \\
\hline $\begin{array}{c}\text { Partial sintering at } 1150^{\circ} \mathrm{C} \text { for } \\
8 Y S Z \text { sample }\end{array}$ & $49 \pm 1$ & 0.09 & 0.99 \\
\hline $\begin{array}{c}\text { Dissolution in nitric acid of Ni for } \\
8 Y \mathrm{YSZ} \text { cermet substrate }\end{array}$ & $63 \pm 3$ & 0.62 & 0.33 \\
\hline $\begin{array}{c}\text { Dissolution in nitric acid of Ni for } \\
\text { 3YSZ cermet substrate }\end{array}$ & 63 & 0.25 & \\
\hline
\end{tabular}

Table 2. Mechanical properties of the investigated samples under micro-compression testing.

\begin{tabular}{|c|c|c|}
\hline Preparation method & $\begin{array}{c}\text { Young's } \\
\text { modulus } \\
{[\mathrm{GPa}]}\end{array}$ & $\begin{array}{c}\text { Compressive fracture } \\
\text { strength } \\
{[\mathrm{MPa}]}\end{array}$ \\
\hline Partial sintering at $1270^{\circ} \mathrm{C}$ & 83 & $1455 \pm 77$ \\
\hline Partial sintering at $1230^{\circ} \mathrm{C}$ & 45 & $950 \pm 5$ \\
\hline Partial sintering at $1200^{\circ} \mathrm{C}$ & 27 & $470 \pm 4$ \\
\hline Partial sintering at $1150^{\circ} \mathrm{C}$ & 13 & $124 \pm 6$ \\
\hline $\begin{array}{c}\text { Dissolution in nitric acid of Ni for 8YSZ } \\
\text { cermet substrate }\end{array}$ & 3.7 & $25 \pm 3$ \\
\hline $\begin{array}{c}\text { Dissolution in nitric acid of Ni for 3YSZ } \\
\text { cermet substrate }\end{array}$ & - & $147 \pm 22$ \\
\hline
\end{tabular}






a)

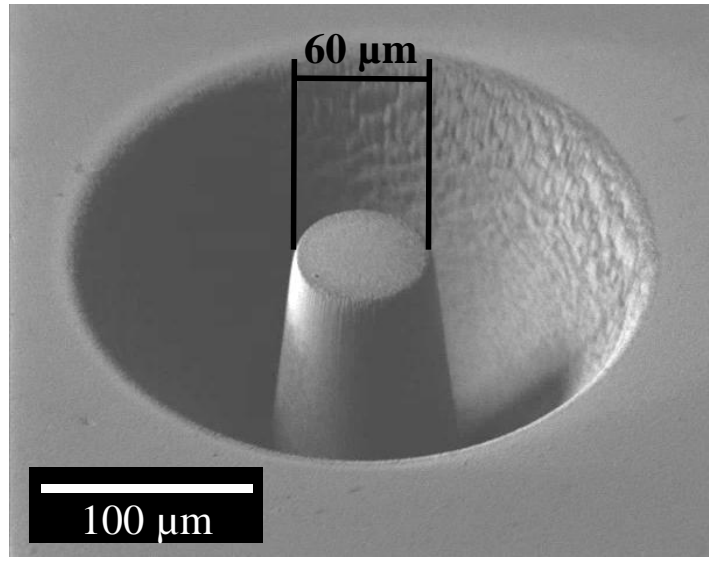

b)

Fig1. Procedure for micro-pillar preparation: a) schematic representation of the $\mathrm{Xe}^{+} \mathrm{pFIB}, \mathrm{b}$ ) example of a typical specimen obtained after the milling. 
a)

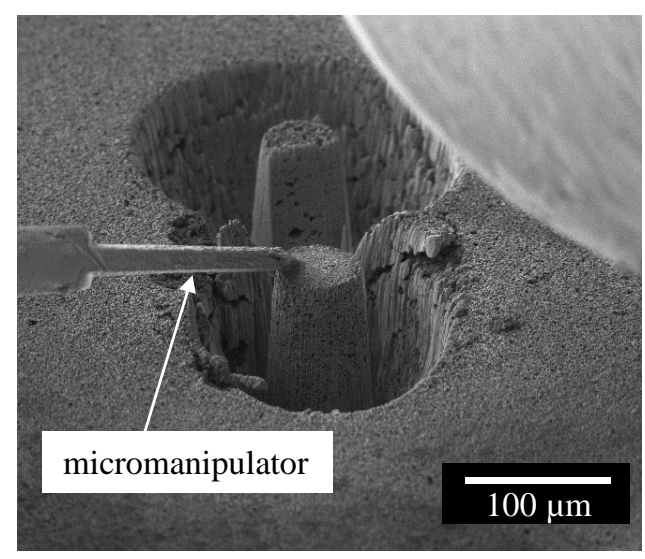

c)

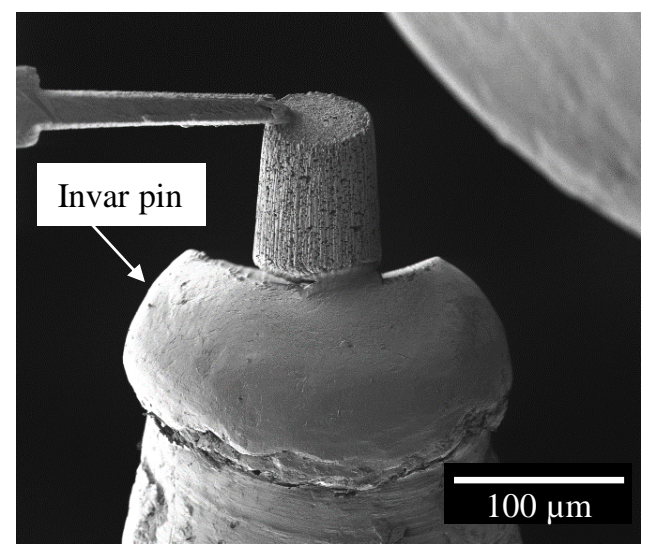

b)



d)

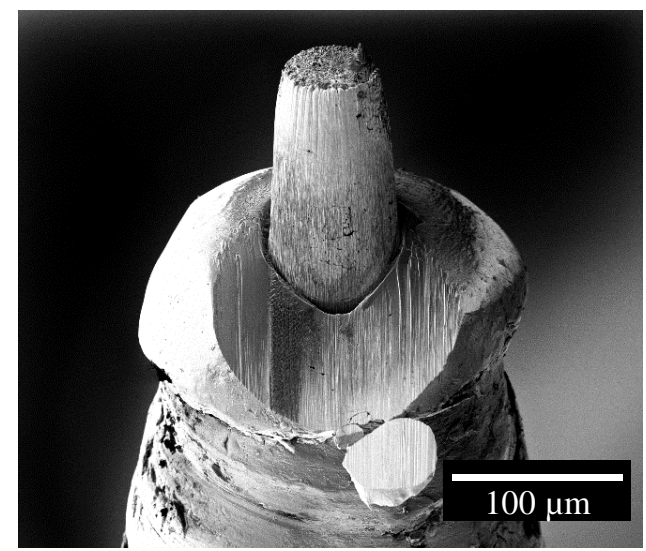

Fig 2. Specimen preparation procedure for X-ray tomography: a) fixation of the micromanipulator on the pillar, b) extraction of the pillar from the pellet, c) pillar moved by the micromanipulator to the invar pin, d) pillar mounted on the invar pin 

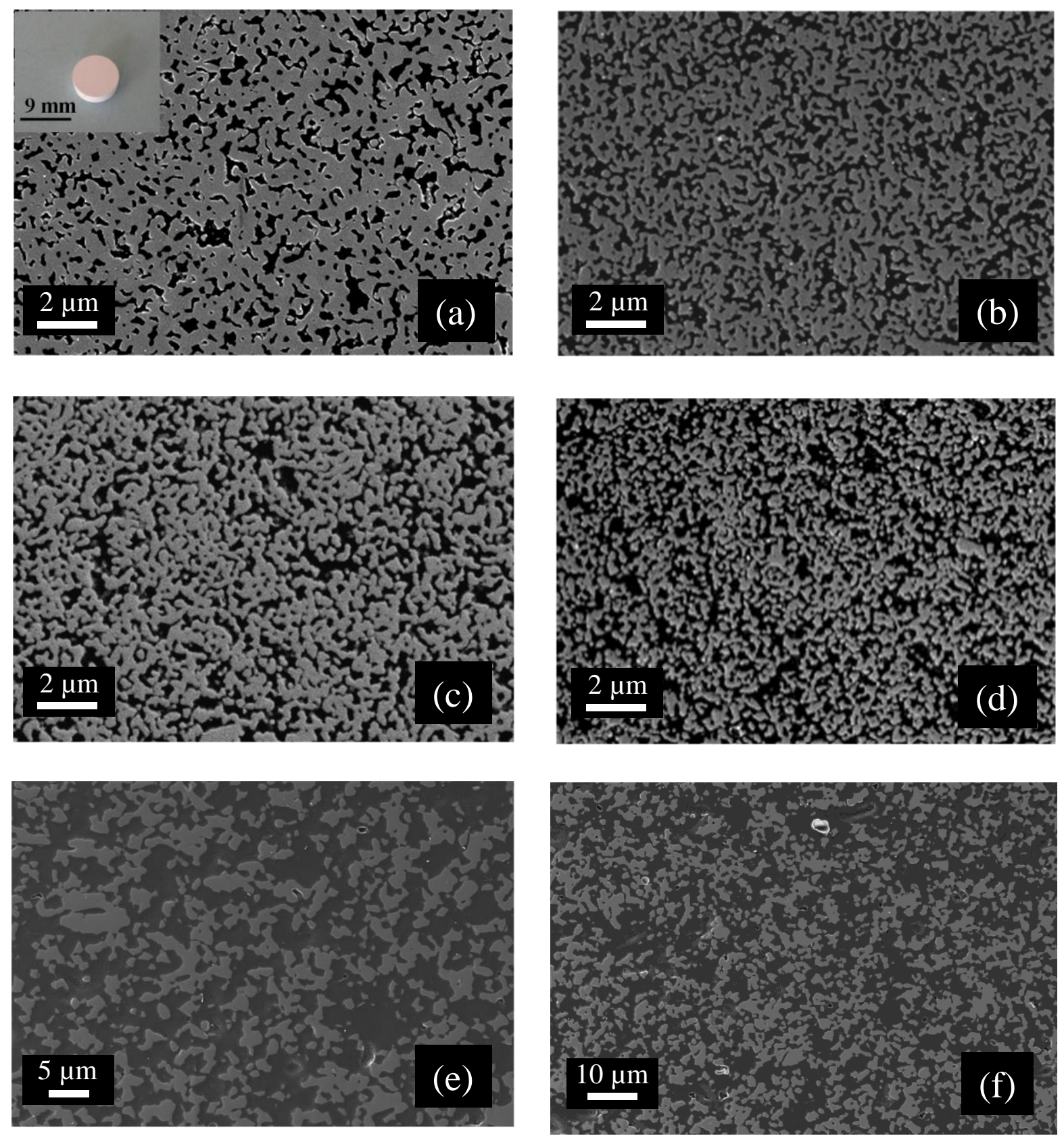

Fig 3. Secondary electrons SEM micrographs of 8 YSZ samples prepared by partially sintering under air at: a) $1270^{\circ} \mathrm{C}$, b) $1230^{\circ} \mathrm{C}$, c) $1200^{\circ} \mathrm{C}$, d) $1150^{\circ} \mathrm{C}$. e) and f) SEM observations of the 8 YSZ sample obtained by dissolving the Ni present in a cermet substrate for two magnifications. The insert in Fig. 3a shows the pellet after sintering. 

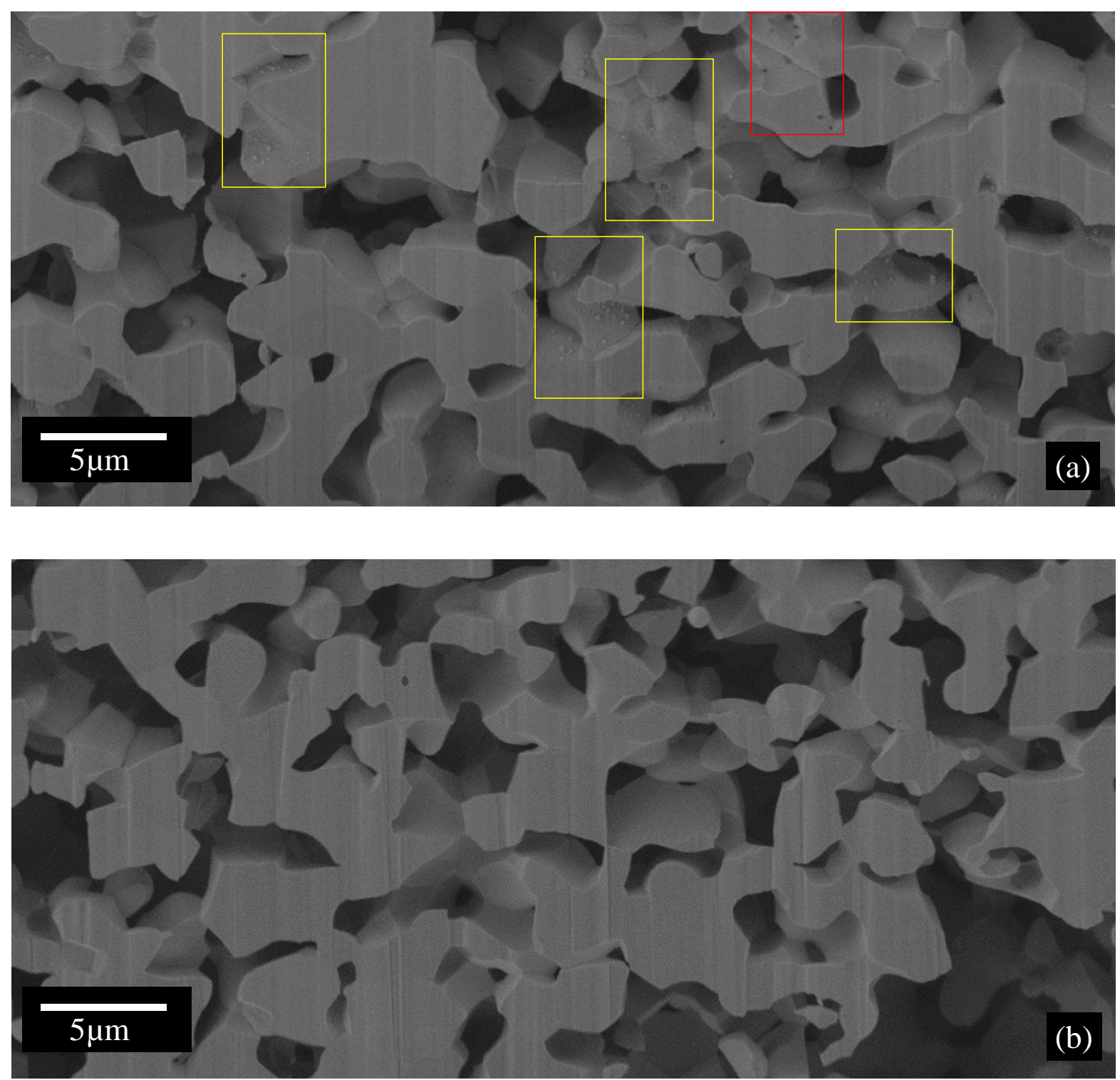

Fig 4. Comparison between two FIB-SEM secondary electron cross-sections of microstructures obtained after dissolution of the $\mathrm{Ni}$ : a) with defects (highlighted by red and yellow rectangles), b) without defects (i.e. obtained by the validated protocol). 

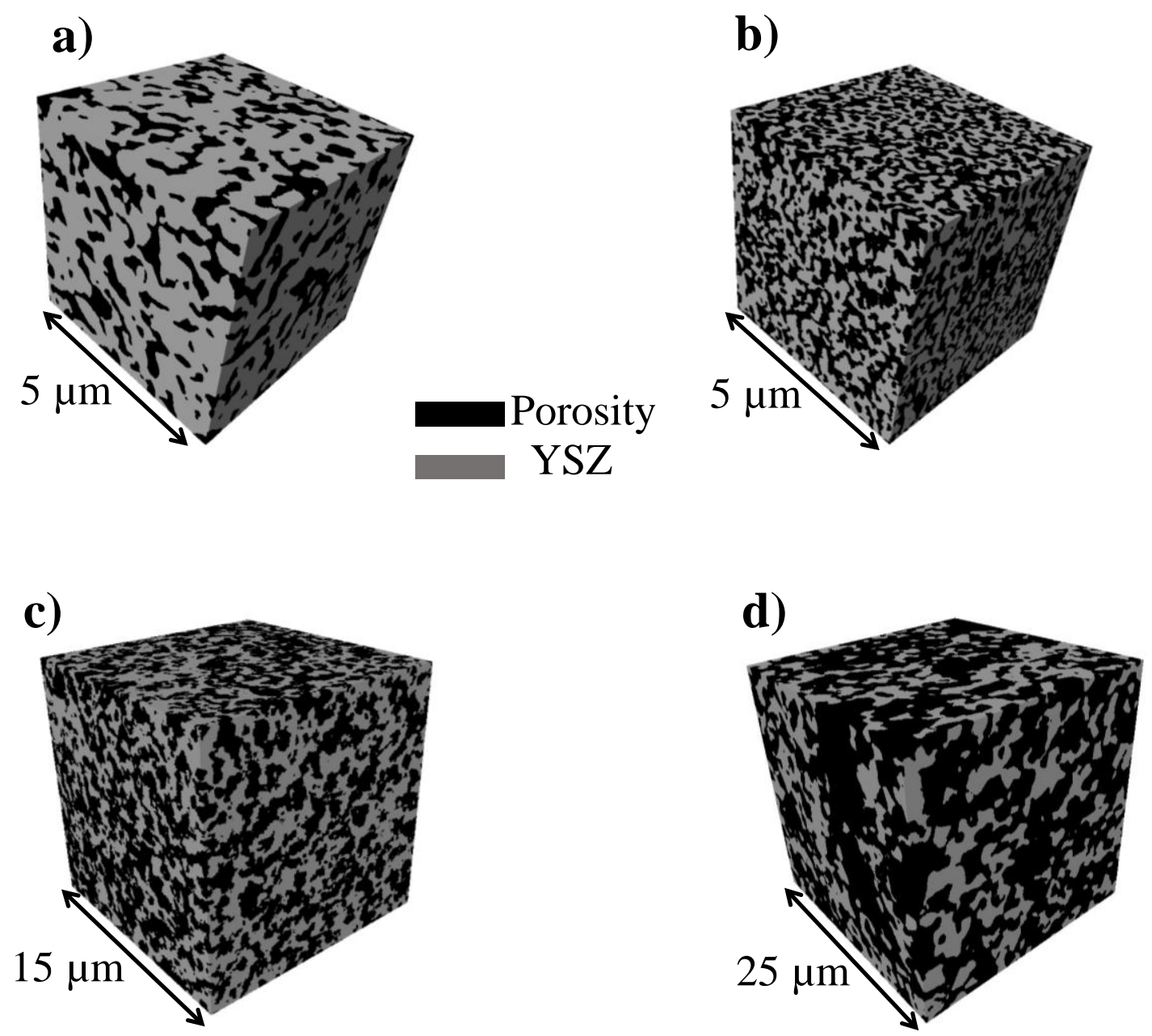

Fig 5. 3D rendering segmented volumes of FIB-SEM reconstructions of porous 8YSZ samples sintered at: a) $1270^{\circ} \mathrm{C}$, b) $1150^{\circ} \mathrm{C}$ and of the whole $\mathrm{X}$-ray holotomography reconstructions for c) highly porous 3 YSZ, d) highly porous 8 YSZ samples. 


\section{a)}
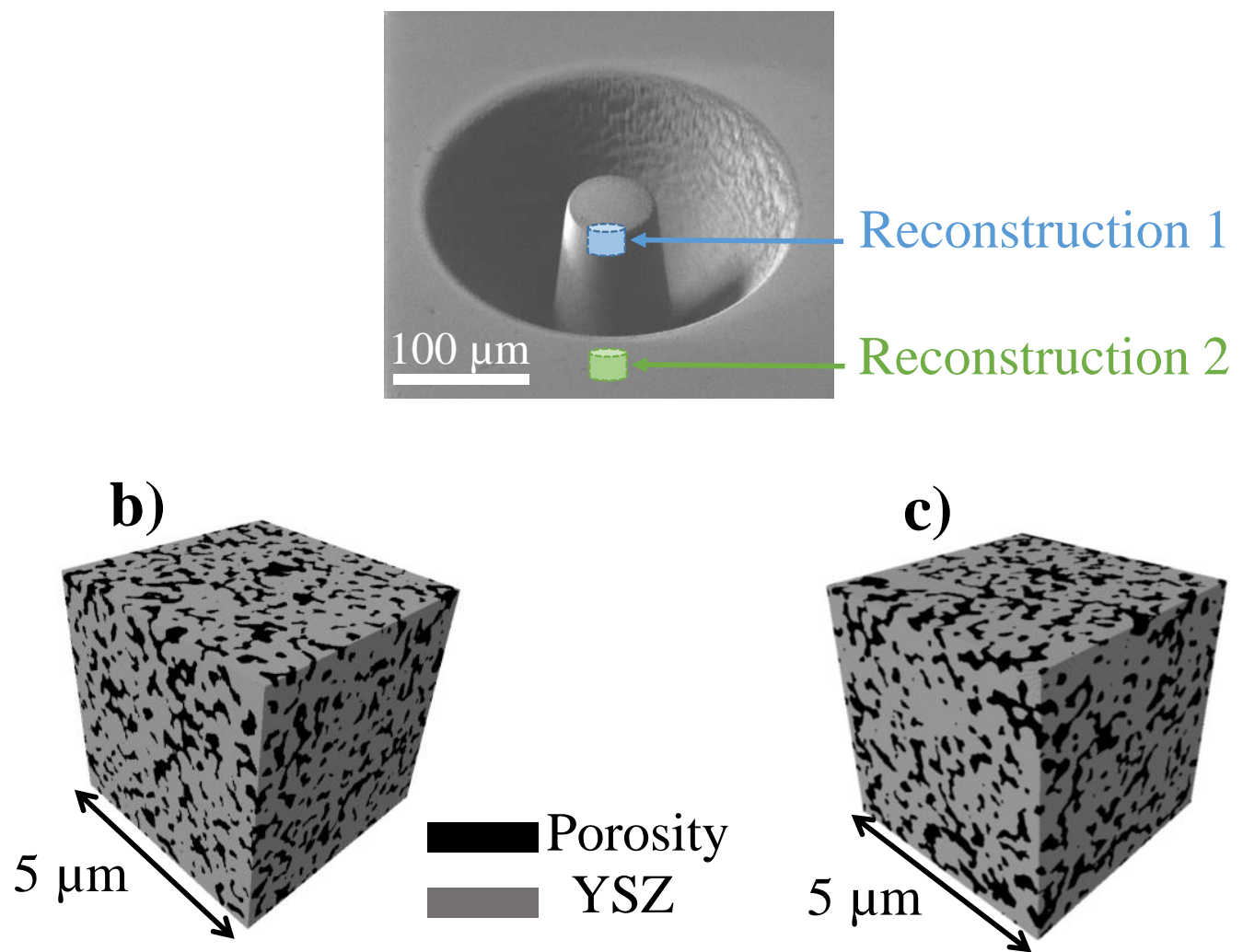

Fig 6. FIB-SEM segmented reconstructions of the sample sintered at $1270^{\circ} \mathrm{C}$ : a) illustration of the two regions of interest, 3D rendering volumes extracted from the whole FIB-SEM reconstructions b) Reconstruction 2: nearby the well in which is the pillar is centered, c) Reconstruction 1: in the pillar. 



Fig 7. Particle size distributions of the solid and porous phases of: a) 8YSZ samples sintered at $1270^{\circ} \mathrm{C}$ (porosity: $33 \%$ ) and $1150^{\circ} \mathrm{C}(49 \%)$, b) highly porous $8 \mathrm{YSZ}$ sample $\left.(63 \%), \mathrm{c}\right)$ highly porous $3 \mathrm{YSZ}$ sample $(63 \%)$. 

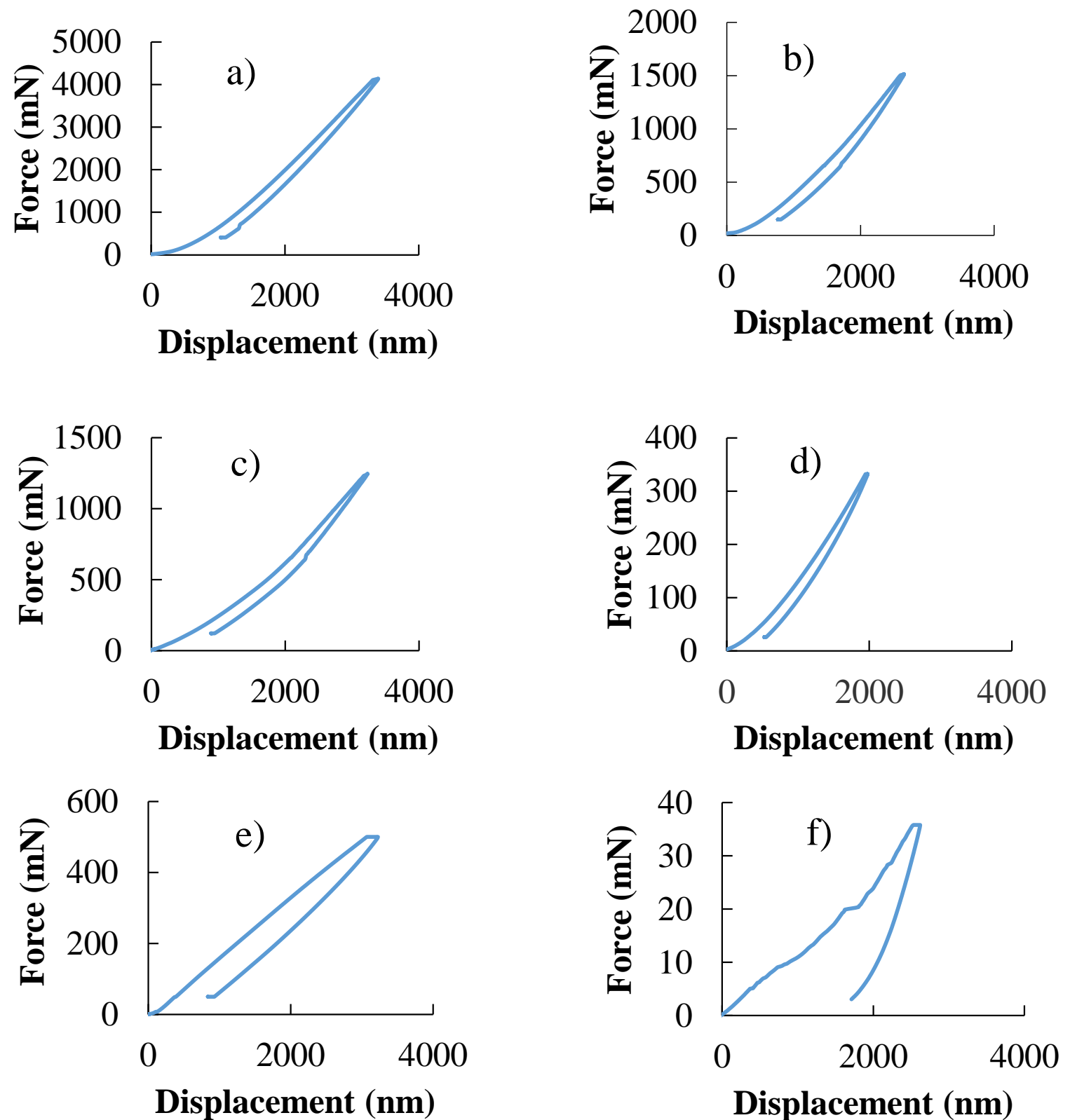

Fig 8. Load-displacement curves recorded for samples sintered at: a) $1270^{\circ} \mathrm{C}$ (porosity: $33 \%$ ), b) $1230(36 \%)$, c) $1200^{\circ} \mathrm{C}(40 \%)$, d) $1150^{\circ} \mathrm{C}(49 \%)$ and highly porous specimens (63\%) made of: e) 3 YSZ, f) 8 YSZ. 


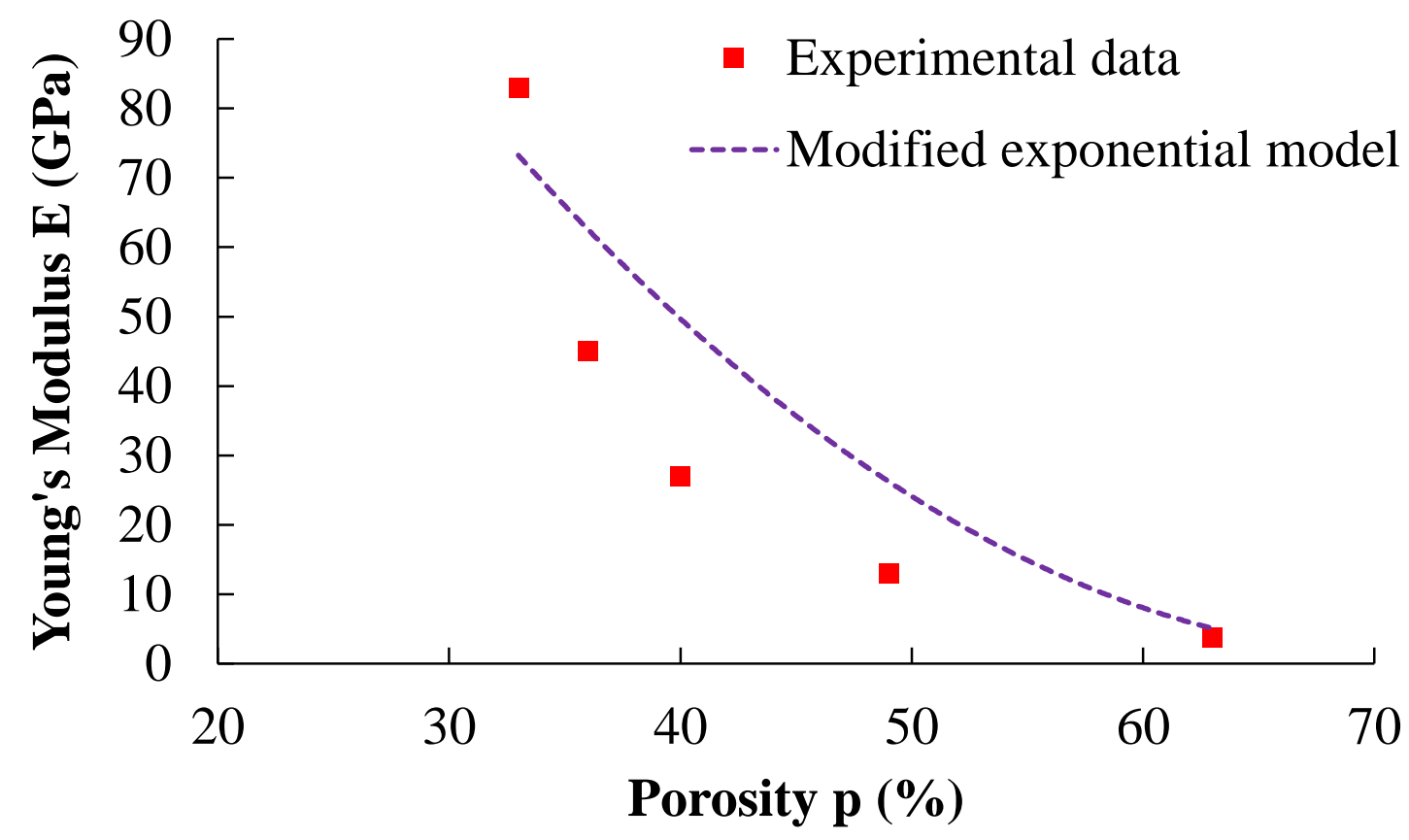

Fig 9. Young's modulus as a function of porosity for 8YSZ porous ceramics. Comparison with the modified exponential model proposed in [62] considering a Young's modulus of $\mathrm{E}_{0}=216 \mathrm{GPa}$ for dense 8YSZ [61] and an intrinsic elastic modulus [E] = 2.2 [62]. 

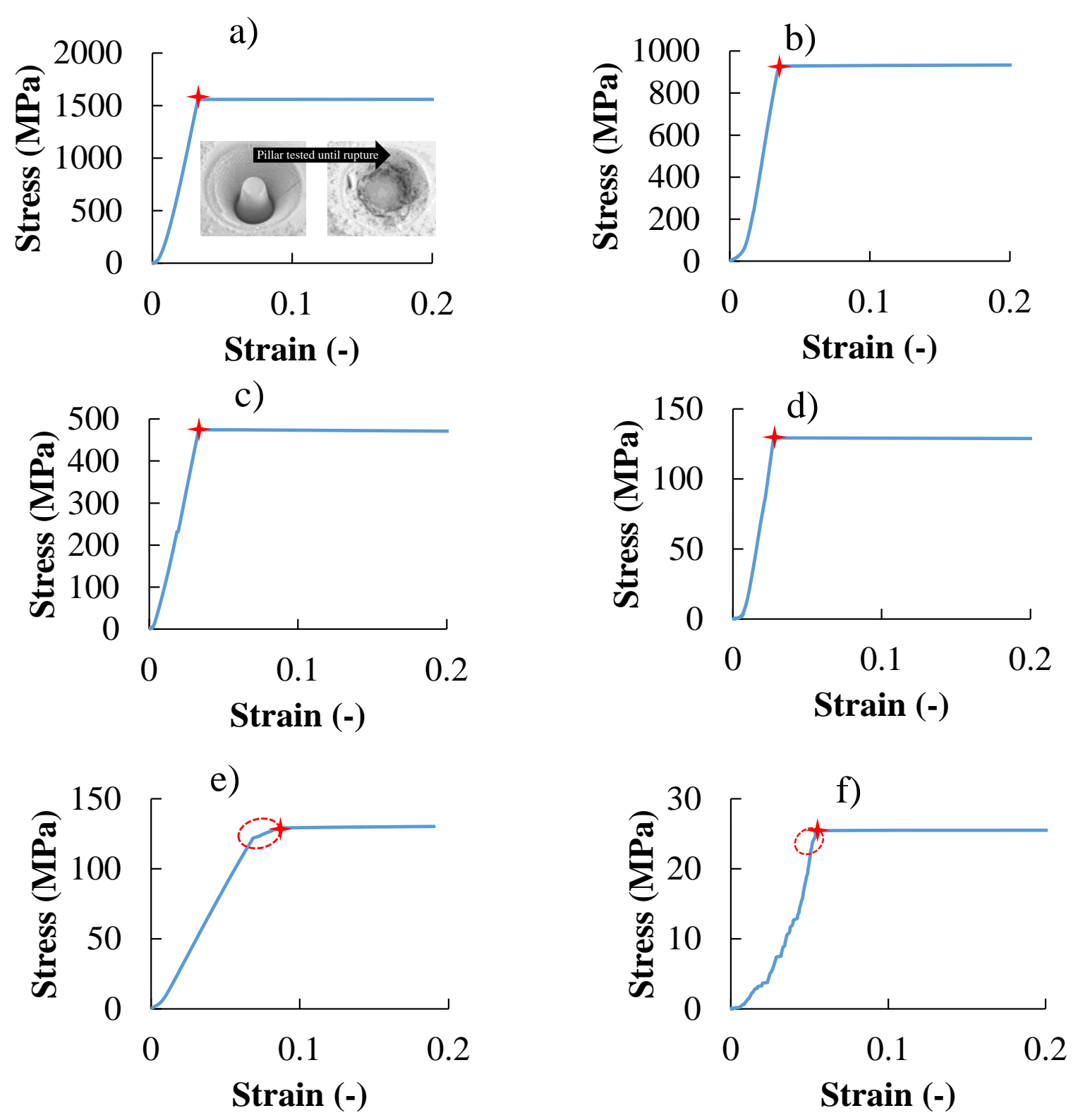

Fig 10. Stress-strain response for the $8 \mathrm{YSZ}$ micro-pillars sintered at: a) $1270^{\circ} \mathrm{C}$ (porosity: $33 \%)$, b) $1230(36 \%)$, c) $1200^{\circ} \mathrm{C}(40 \%)$, d) $1150^{\circ} \mathrm{C}(49 \%)$ and for the highly porous specimens (63\%) made of: e) 3YSZ, f) 8 YSZ. Fracture stress is marked with a star. The zone surround by the dashed line in e) and f) shows non-linearity in the stress strain curve before fracture. 


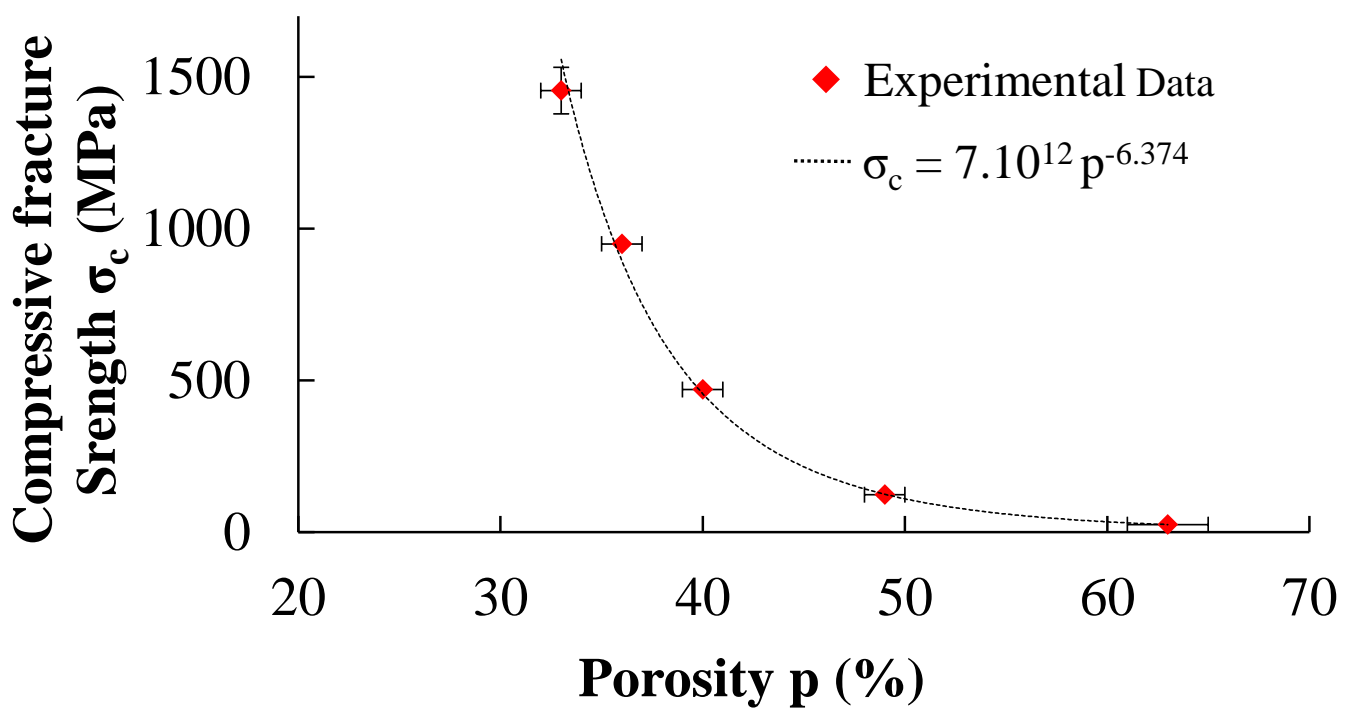

Fig 11. Compressive fracture strength as a function of porosity in 8 YSZ ceramics, fitted by a power law model. 


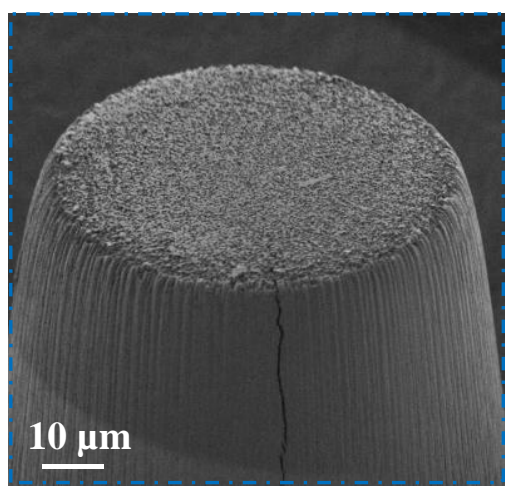

a)

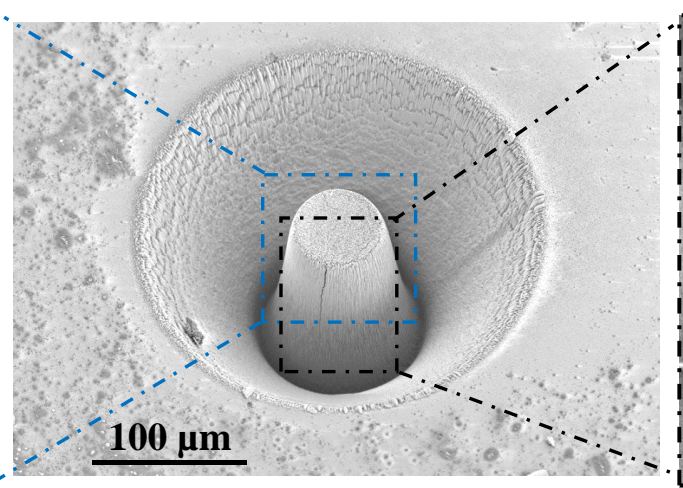

b)

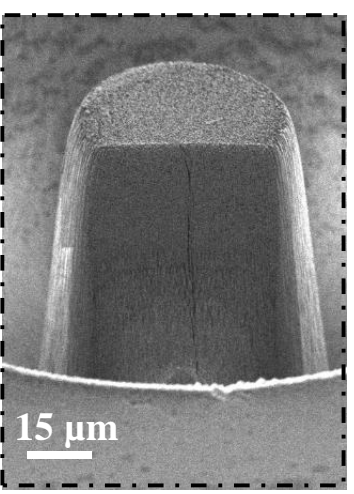

c)

Fig 12. Ex-situ characterization after mechanical loading of the 8YSZ pillar sintered at $1270^{\circ} \mathrm{C}$ (porosity: $33 \%$ ): a) SEM image of a longitudinal crack on the edge of the pillar, b) SEM image of the tested pillar, c) FIB-SEM cross section showing the large crack in the bulk of the pillar. 

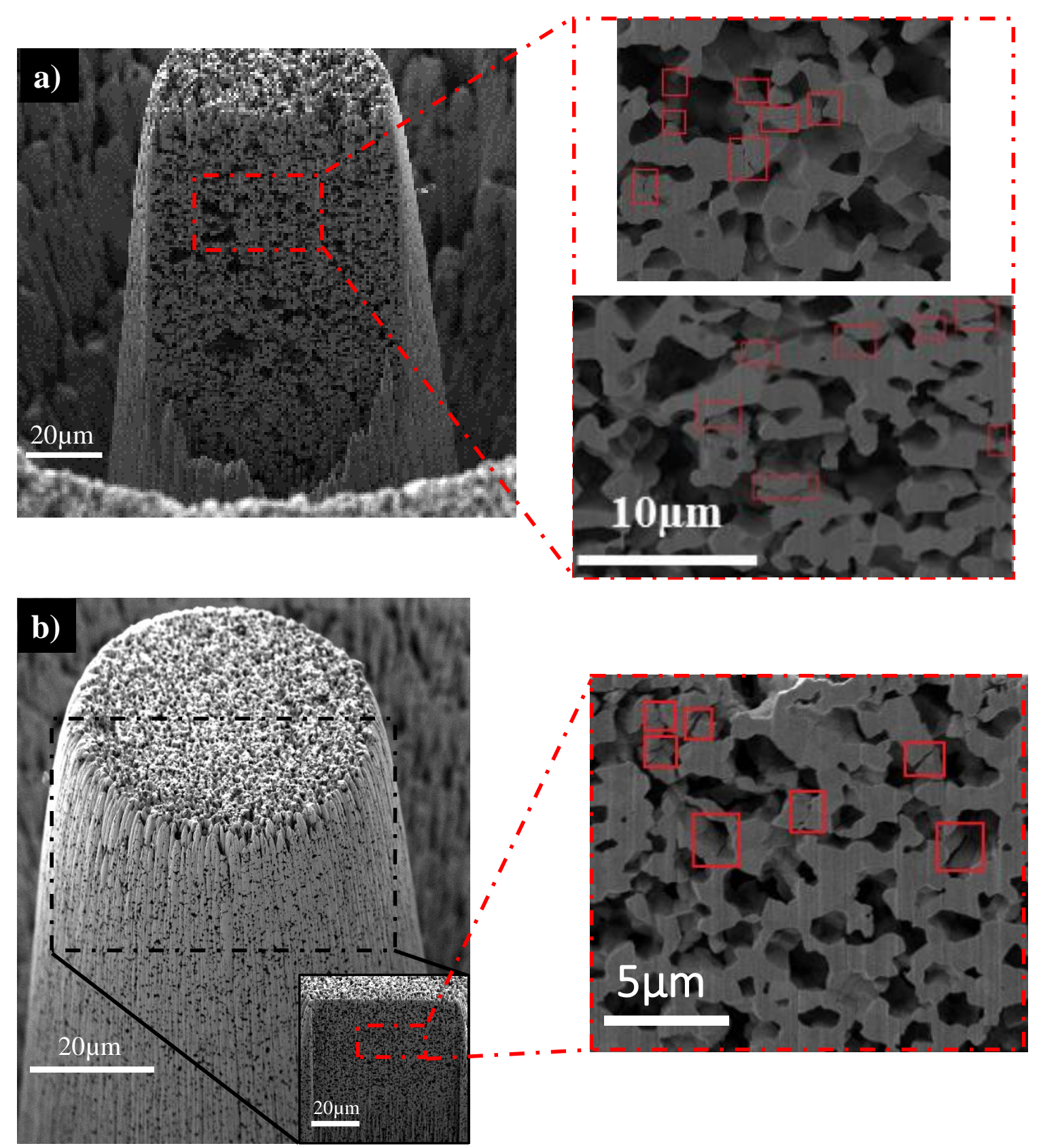

Fig 13. Ex-situ characterization of the highly porous (porosity: 63\%) pillars after the mechanical loading with a zoom showing micro-cracks in the bulk of the pillar (highlighted by red rectangles): a) 8YSZ, b) 3 YSZ. The tests were stopped before the fracture. 